\title{
Del castro al puerto: la villa de Burela y los orígenes del poblamiento medieval del litoral cantábrico gallego ${ }^{1}$
}

\author{
Carlos Baliñas Pérez²; Carlos Andrés González Paz ${ }^{3}$
}

Recibido: 05 de diciembre de 2016 / Aceptado: 15 de marzo de 2017

Resumen. El objetivo principal del artículo es ofrecer un estudio centrado en la evolución histórica de la ocupación humana en el ámbito geográfico de Burela (Lugo) y, a través de la observación, descripción y análisis del caso concreto, avanzar en el conocimiento del poblamiento medieval del litoral cantábrico gallego.

Palabras clave: Galicia; Burela; Edad Media; evolución; poblamiento; territorio; litoral.

\section{[en] From the Hillfort to the Port: the Town of Burela and the Origins of the Medieval Settlement along the Cantabrian Coast of Galicia}

\begin{abstract}
The main purpose of the article is to contribute a study focusing on the historic development of human occupation in the geographical area of Burela (Lugo) and, through case study observation, description and analysis, contribute to the advancement of knowledge about Medieval settlements on the Cantabrian coast of Galicia.
\end{abstract}

Keywords: Galicia; Burela; Middle Ages; Development; Settlement; Territory; Coastline.

Sumario: 1. El paisaje histórico local: los primeros testimonios de ocupación antrópica del espacio. 2. Las unidades de ocupación y estructuración del paisaje histórico local en la Alta y Plena Edad Media (siglos X-XII). 3. La "Suçesion de Burela": señorialización laica y patrimonialización territorial (siglos XIII-XV). 4. El paisaje histórico local tardomedieval (siglos XV-XVI): la evolución y configuración territorial de una entidad polinuclear (Burela do Cabo, Vila do Medio, Puerto de Burela y Vilar). 5. Bibliografía.

Cómo citar: Baliñas Pérez, C.; González Paz, C.A. (2017) Del castro al puerto: la villa de Burela y los orígenes del poblamiento medieval del litoral cantábrico gallego, en En la España Medieval 40, 375-407.

Este artículo se ha realizado parcialmente en el marco del proyecto de investigación "Las peregrinaciones a Santiago de Compostela en la España de la segunda mitad del siglo XIX: entre tradición y modernidad en el contexto europeo" (MINECO, Programa Estatal de Fomento de la Investigación Científica y Técnica de Excelencia, Subprograma Estatal de Generación de Conocimiento, 2015-2017, IP: Dr. Antonio Manuel Pazos Rodríguez (CSIC), referencia: HAR2014-58753-P).

2 Universidade de Santiago de Compostela carlos.balinas@usc.es

3 Instituto de Estudios Gallegos Padre Sarmiento, Consejo Superior de Investigaciones Científicas (CSIC) carlosandres.gonzalez@iegps.csic.es 
Pasado este río de Espineira vna legua adelante se entra en el mar otro río que dizen Fozdouro, no tieniendo ninguna poblaçión en su orilla. De él a dos leguas aze la costa vn puertizuelo que dizen puerto de Burela. Junto a él está vna aldea de pescadores del mismo nonbre, tomándolo, así el puerto como la aldea, de vn lugar que queda media legua tierra adentro que llaman Burela. Deste puerto media legua ase la costa vn cabo muy conoçido y demarcado de los nauegantes por ser alto y mitido en el mar. Corre este cabo de Burela con el que queda dicho de Peñas, en la tabla del Prinçipado de Asturias, leuante y poniente, bente y dos leguas distante el uno del otro. Hun buen quarto de legua de la punta deste dicho cabo de Burela están tres yslotes del mismo nonbre y, pasado este dicho cabo, se ynclina la costa al mediodía 4 .

Esa referencia geográfica se incluye en la Descripción de España y de las costas y puertos de sus reynos (1634), concretamente en los folios dedicados a la "costa, puertos y lugares dellos del reyno de Galizia", del cartógrafo portugués Pedro Teixeira Albernaz.

Allende de avanzar someramente algunas cuestiones objeto de este artículo -temáticamente centrado en el estudio de la conformación y configuración del poblamiento medieval de Burela, topónimo actualmente común a localidad, feligresía y término municipal-, en esa cita se señala un factor que resultará relevante en el análisis histórico de la ocupación antrópica de este sector de la costa lucense: el medio natural. Sin duda, entre los elementos caracterizadores de la geomorfología de esta área territorial -en cierto sentido, condicionantes básicos del asentamiento humano y de los diferentes hábitats constituidos en distintas cronologías-, sobresalen la abundancia de cabos y puntas en un litoral bastante regular ${ }^{5}$ y su calidad de límite occidental de la "rasa cantábrica".

Esa circunstancia no ha pasado desapercibida a la contada bibliografía aparecida en las últimas décadas, si bien cuestión aparte sea el grado de análisis de su impacto. En ese sentido, y en términos generales, la conversión de Burela -conceptualizada como sujeto histórico- en objeto historiográfico se remontaría a 1985, cuando salía a la luz el folleto titulado Burela, del sacerdote Ricardo Pena Domínguez, un acercamiento a su trayectoria cronológicamente transversal, condensado en una treintena de páginas y un apéndice fotográfico.

Once años más tarde, después de su segregación -acontecida en 1994- y transformación en municipio, la revista Lucus centraba el suplemento monográfico de su número 43 en Burela, destinándose una quincena de páginas de autoría colectiva a la síntesis de su historia y descripción de su patrimonio artístico ${ }^{7}$.

Traspasado el umbral del nuevo milenio, concretamente en 2004, se publicaba el libro Burela. Apuntes históricos y crónica del siglo XX, obra póstuma de Ricardo Pena Domínguez, una extensa y laudable miscelánea de datos, noticias y referencias históricas que, sin grandes ambiciones críticas, metodológicas ni paradigmáticas, resultaba de la ardua labor de su primer cronista oficial.

\footnotetext{
Zolle [Betegón], "Transcripción”, p. 325.

Rodríguez Lestegás, “A Galicia cantábrica”, pp. 20, 24-26, 28-29, 36-40 y 49-50.

"Las "rasas" son "superficies planas que se sitúan entre el borde acantilado y las estribaciones montañosas del interior, con una pendiente sumamente suave hacia el mar". Flor [Rodríguez], "Las rasas asturianas", pp. 65-81. Burela (Lugo), pp. 15-29.
} 
Finalmente, al año siguiente, esta localidad del cantábrico lucense era la sede de la segunda edición de las Xornadas de Estudios Medievais da Mariña Central, foro académico cuyas sesiones versaron sobre diferentes aspectos relativos a la economía comarcal medieval ${ }^{8}$.

Con este artículo, nuestro principal objetivo es ofrecer un estudio centrado en la evolución histórica de la ocupación humana en el ámbito geográfico de Burela y, a través de la observación, descripción y análisis de este caso concreto, continuar avanzando en el conocimiento del poblamiento medieval del litoral cantábrico gallego, un territorio de gran interés y potencial, mas todavía bastante huérfano de atención desde una perspectiva historiográfica especializada.

Con ese objetivo en mente, hemos intentado formular un discurso histórico inclusivo, basado substancialmente en el análisis exhaustivo de los testimonios documentales (inéditos y publicados) y literarios (cronísticos) disponibles. Asimismo, hemos recurrido a las fuentes de información aportadas por la arqueología y la geografía física que, aún encontrándose virtualmente en ciernes en lo relativo a esta zona del septentrión galaico, pueden proporcionar datos de carácter esencial para nuestra propuesta de conocimiento.

Figura 1. Burela (localización)9.

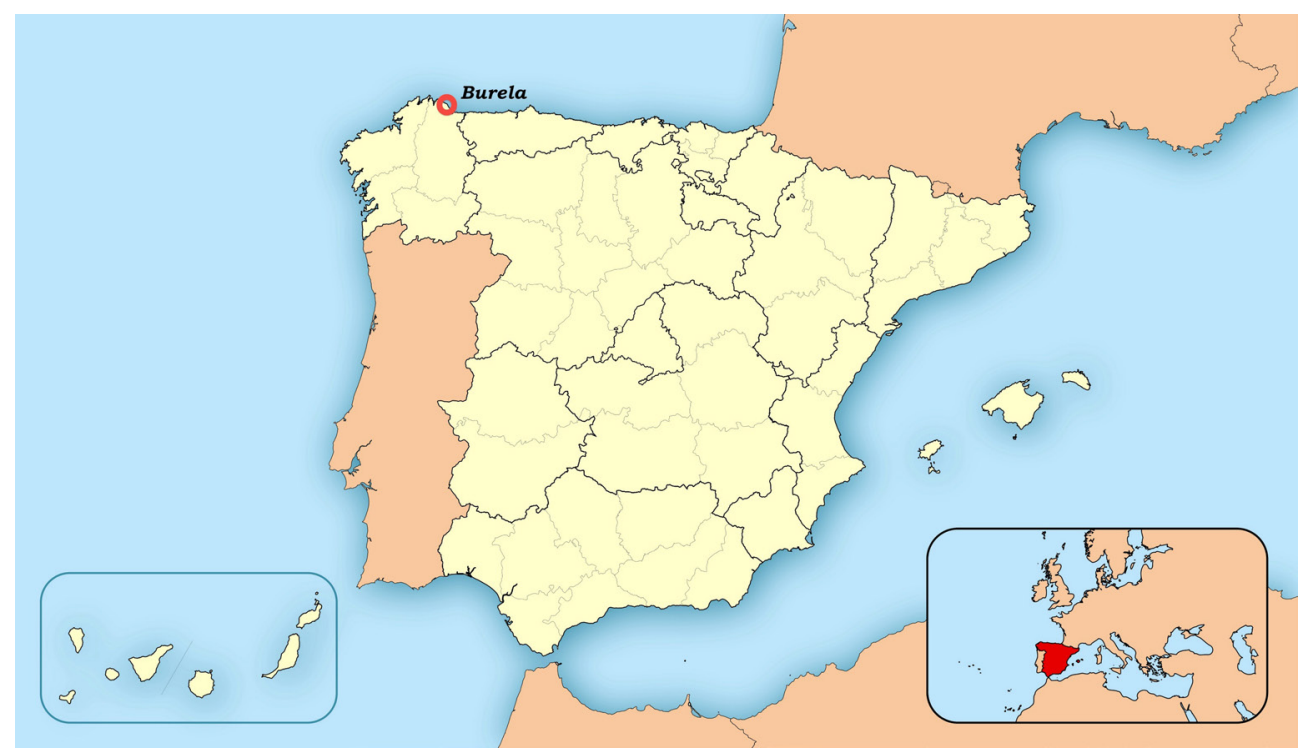

8 Se desarrollaron durante los días 21, 22 y 23 de octubre de 2005, concurriendo como ponentes, entre otros, Eduardo Pardo de Guevara y Valdés, Xosé Antón García González-Ledo, César Olivera Serrano, Felipe Valdés Hansen, Carlos Baliñas Pérez, Carlos Andrés González Paz, María Xosé Rodríguez Galdo, Anselmo López Carreira, Isidro García Tato, Gloria de Antonio Rubio y Juan Ramón Fernández Pacios.

9 Mapa de localización de España, by HansenBCN (Own work) [Public domain], via Wikimedia Commons, https://commons.wikimedia.org/w/index.php?curid=3944708. 
Figura 2. Burela (localización) ${ }^{10}$.
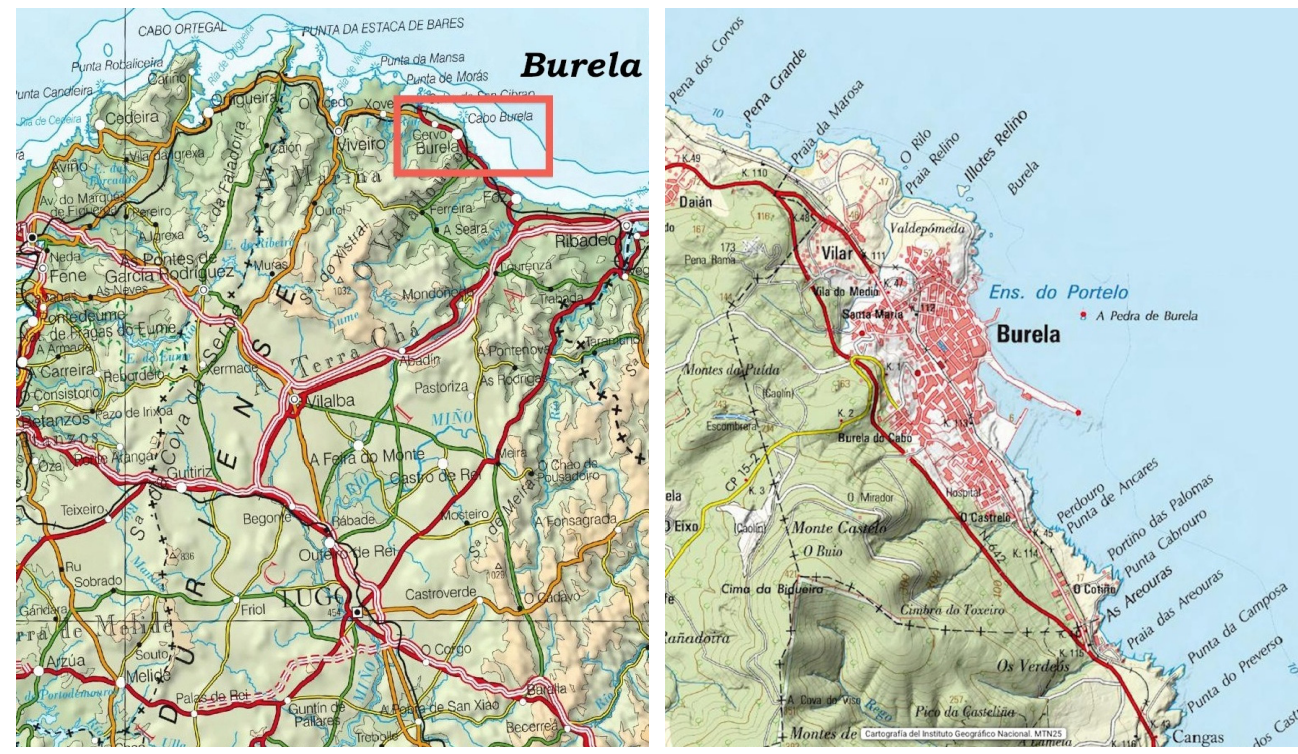

\section{El paisaje histórico local: los primeros testimonios de ocupación antrópica del espacio}

En el transcurso de los últimos treinta años, la prospección arqueológica del territorio ha facilitado la realización de avances cualitativos en el conocimiento del hábitat castreño y romano en el área cantábrica gallega.

Sus análisis han ofrecido a la investigación arqueohistórica información significativa sobre tres tipos de yacimientos localizados entre los ríos Eo (al este) y Mera (al oeste): asentamientos castreños costeros de heteróclita adscripción temporal y, con cronología específicamente romana, factorías de producción y comercialización de salazón de pescado, y villae a mare, establecimientos rurales litorales, vinculados al medio marino circundante, que solían organizarse internamente en dos áreas funcionales: residencial y productiva ${ }^{11}$.

Si el objetivo se focaliza en el actual término municipal de Burela -cuya extensión es de apenas 8,2 kilómetros cuadrados-, se infiere la relativamente intensa ocupación de su franja litoral, registrándose una serie de asentamientos que se describirán brevemente a continuación.

En primer lugar, el Castro de Cabo Burela, que cuenta con una pequeña "croa" o acrópolis -de 70 m. (eje E-O) x $60 \mathrm{~m}$. (eje N-S)- y dos terrazas anejas al levante ${ }^{12}$, habiéndose descubierto en este emplazamiento un petroglifo de cazoletas ${ }^{13}$. En segundo lugar, el Castro de Chao do Castro, que dispone de una amplia "croa" central, rodeada de varias terrazas escalonadas y defendida mediante un terraplén sencillo ${ }^{14}$.

\footnotetext{
10 Mapa Topográfico Nacional 1:500.000 (MTN500). Mapa Topográfico Nacional 1:25.000 (MTN25). Cartografía (C) Instituto Geográfico Nacional de España.

11 Pérez Losada, Fernández Fernández y Vieito Covela, “Toralla”, pp. 481-493.

12 Xunta de Galicia, GA27902001. Concello de Burela, 101.

13 Ibidem, GA27902006. Ibidem, 106.

14 Ibidem, GA27902002. Ibidem, 102. En esta zona del litoral burelense se encontraron, a mediados del siglo XX,
} 
En tercer y último lugar, contigua a la Punta de O Castrelo ${ }^{15}$, se halla la Punta de O Campón, en la cual se localiza un yacimiento -conocido como Castro de O Campón ${ }^{16}$, cuya singular configuración y cronología sobresalen entre los parámetros locales. En una prospección arqueológica inicial, se subrayó la hipotética existencia de una estancia dotada de un sistema de calefacción tipo hipocausto, de adscripción crono-cultural romana ${ }^{17}$.

Los sondeos y excavaciones ulteriores en O Campón confirmaron, en un primer instante, la presencia de dos salas caldeadas de época romana -datadas aproximadamente en el siglo IV d.C. ${ }^{18}$-, dos hipocaustos realizados con materiales reutilizados procedentes de estructuras anteriores. En un segundo momento, avanzadas las investigaciones, se constató un nivel con cerámica castreña empleado como relleno de regularización del terreno, indiciario de la existencia de una fase de ocupación temprana, situada en el cambio de era o en el siglo I d.C. Asimismo, se evidenció la presencia de un conjunto principal -con dos estancias rectangulares dotadas del sistema de calefacción descrito- que se imbricaría en la zona residencial de un asentamiento cronológica y culturalmente romano, acompañado de un área funcional, quizás vinculable a un espacio de trabajo, atestiguándose en general diferentes fases constructivas y remodelaciones ${ }^{19}$.

Sobre la consideración tipológica de los restos arqueológicos descubiertos, ciertos autores han propuesto su identificación con unas posibles termas en una probable villa a mare $^{20}$. Quizás, esa indeterminación sería superable si se aglutinasen las características y variables endógenas y exógenas asociadas al enclave y, a continuación, se abriese una línea de prospección y contextualización mixta, en la cual este asentamiento burelense se sometiese a un análisis comparado, estableciéndose como términos de contraste otros yacimientos del litoral cantábrico gallego de cronologías equiparables ${ }^{21}$.

La aplicación de esa metodología -someramente esbozada en estas páginas- al septentrión lucense durante la Temprana Edad Media -concretamente a la franja costera localizada entre las desembocaduras de los ríos Eo (al este) y Mera (al oeste)- se ha llevado a la práctica recientemente por vez primera ${ }^{22}$. Los resultados obtenidos mues-

una arracada y un torques datados entre los siglos III y I a.C. Balseiro García, El oro prerromano, pp. 138-147 y 282-289. Sobre el lugar ("Chao do Castro"/“Os Castrillós") y tiempo concretos del hallazgo del torques (sometidos a discusión en los últimos años), consúltese: CulturaGalega, "As xoias do tesouro".

15 En esta área peninsular, concretamente en la zona más próxima al acantilado, se localizaría el Castro de O Castrelo. Sin embargo, salvo la indicación toponímica, aún no se han evidenciado restos materiales de su existencia. Xunta de Galicia, GA27902004. Concello de Burela, 104.

16 Ibidem, GA27902003. Ibidem, 103.

17 Xunta de Galicia, CJ102A99/219-0. González Fernández y Ricart Guillot, Prospección arqueológica.

18 González Soutelo y Fernández Pintos, "Los pavimentos romanos”, pp. 322-329. En este trabajo, las autoras señalan dos abanicos temporales: "s. III-V d.C.” (p. 324) y "siglos IV-V d.C.” (p. 329).

19 Xunta de Galicia, CJ102A2004/301-0. Fernández Pintos, Sondeos valorativos, pp. 39-40. Segunda fase, pp. 37-43.

20 Pérez Losada, Fernández Fernández y Vieito Covela, “Toralla”, pp. 488-490. González Soutelo, El valor del agua, pp. 182-183.

21 La relación de yacimientos de interés se puede consultar en: Arias Vilas, “A Mariña lucense”, pp. $261-276$. Cordeiro Maañón, “Análisis de los asentamientos”, pp. 93-122. Sobre la presumible existencia de una "vía da costa no sector lucense”, véanse: Rodríguez Colmenero, Ferrer Sierra y Álvarez Asorey, Miliarios, pp. 723-724. Gómez Vila, Vias romanas, pp. 262-275. El autor de esta tesis doctoral -realizada bajo la dirección académica del Prof. Dr. José Manuel Caamaño Gesto- data el ara a los lares viales descubierta en el monte de Tagarreiros (Santiago de Sargadelos, Cervo, Lugo) en el siglo II d.C. Ibidem, núm. CICLV4, pp. 268-269 y 310.

22 González Paz, O bispado de Mondoñedo. Tesis doctoral realizada bajo la dirección académica del Prof. Dr. Carlos Baliñas Pérez. 
Figura 3. Castro de Cabo Burela y Castro de Chao do Castro ${ }^{23}$.
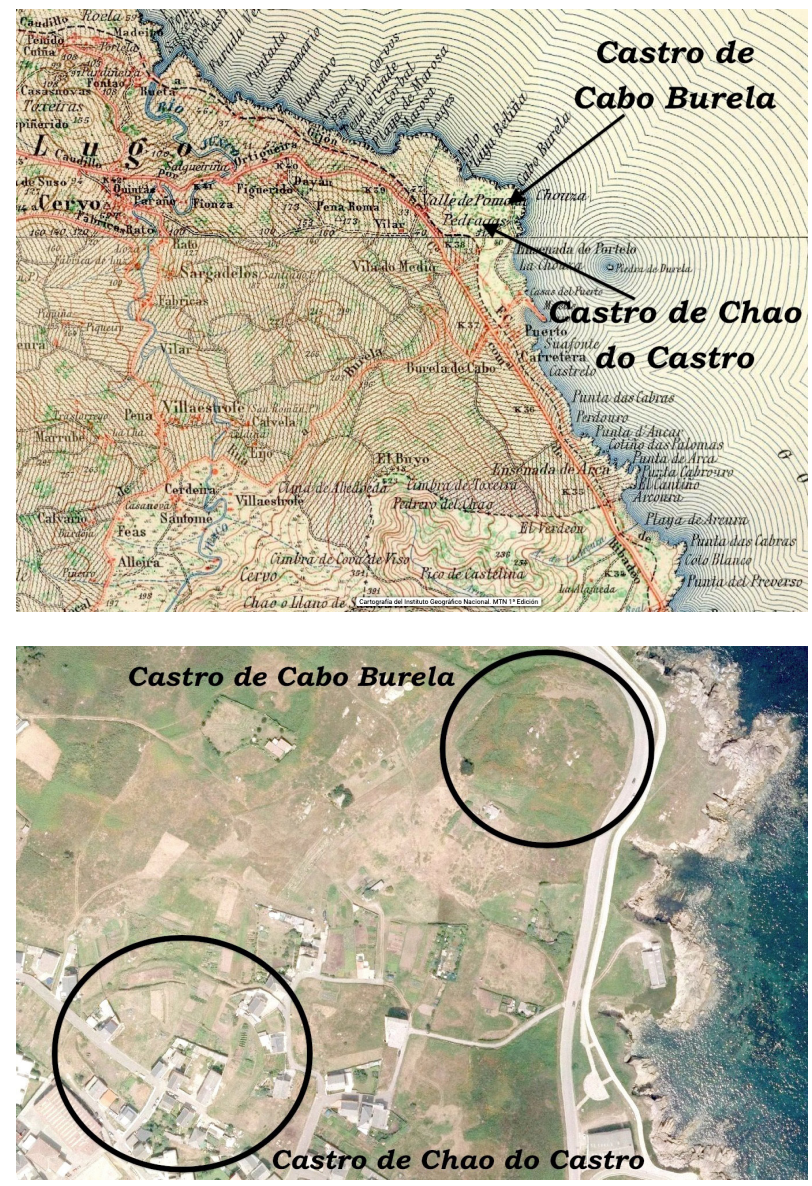

tran, en términos relativos, un período comprendido entre los siglos V y VII d.C., un momento histórico complejo que se caracteriza, al mismo tiempo, por un doble proceso de cambio y adaptación ${ }^{24}$.

Por una parte, el abandono coyuntural de establecimientos habitacionales y productivos litorales entre comienzos del siglo $\mathrm{V}$ y mediados del siglo VI, debido a la conjunción de cuestiones climatológicas (descenso de las temperaturas, aumento del

23 Mapa Topográfico Nacional 1:50.000 (MTN50). $1^{\text {a }}$ ed. Cartografía (C Instituto Geográfico Nacional de España. PNOA cedido por (C) Instituto Geográfico Nacional de España.

24 Fábrega Álvarez, Poblamiento y territorio. Fernández Ochoa, "Materiales arqueológicos”, III, pp. $173-188$. Fernández Ochoa y Morillo Cerdán, "La ruta marítima", pp. 225-231. Maciñeira y Pardo de Lama, Bares. Novo Güisán, "Las ruinas de la playa de Area", pp. 467-505. Ramil González, Historia de Cariño. Inventario do patrimonio cultural. "Intervención arqueolóxica", pp. 175-178. "I Campaña de excavación", pp. 215218. Ramil González y Picos Brage, Escavación arqueolóxica. Ramil González... [et al.], "Villa romana de Bares”, pp. 185-224. Ramil Rego... [et al.], "El yacimiento de Punta do Castro”, pp. 87-115. Rodríguez López, Vázquez Varela y Camino Mayor, "Concheros castreños y romanos”, pp. 61-73. Rodríguez Resino, Do Imperio Romano á Alta Idade Media, pp. 56-58 y 165-166. Romero Masiá, “Asentamentos castrexos costeiros”, pp. 61-80. Vázquez Varela y Rodríguez López, "Nuevos datos”, pp. 91-123. "El aprovechamiento de los recursos marinos", pp. 335-365. 
nivel del mar y elevación de la línea de la costa, causa de la mayor incidencia de los temporales marítimos sobre las estructuras naturales y antrópicas) y a la transformación del mar en una amenaza (ataques piráticos) ${ }^{25}$, y su reocupación efectiva tras la normalización de la situación a partir de mediados del siglo $\mathrm{VI}^{26}$.

Por otra parte, el transvase del hábitat antropogénico desde la línea de la costa al inmediato interior -la seguridad se buscaba en la distancia relativa del litoral ${ }^{27}$-, eso sí, sin que los nuevos emplazamientos acostumbrasen a desvincularse económicamente del medio marino. Dentro de estos parámetros, como se expondrá a continuación, se podría enmarcar la evolución de este sector concreto del litoral cantábrico en las centurias altomedievales.

Figura 4. Castro de O Campón ${ }^{28}$.
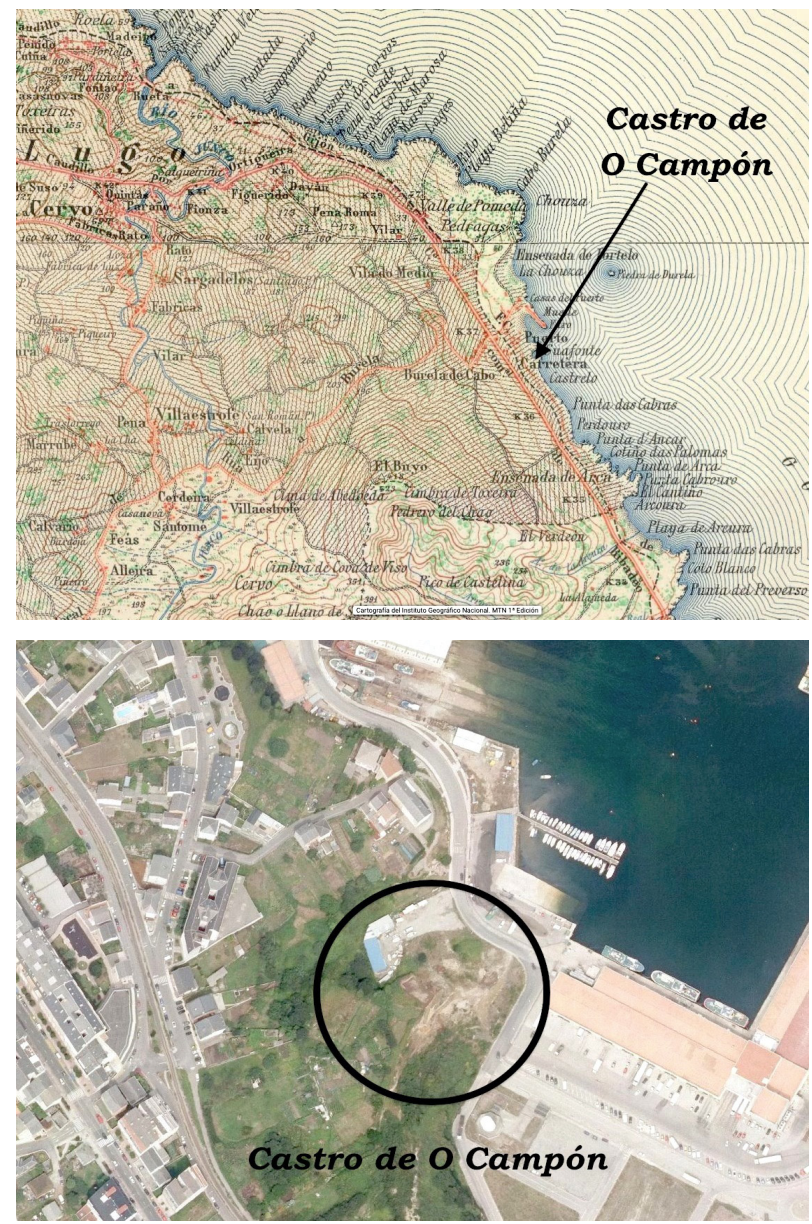

25 Sobre dos ataques hérulos a las costas lucenses -Lucensi litore y maritima conuentus Lucensis loca-, acaecidos en los años 455 y 459, véase: Hydace, Chronique, § 171 y 194, Tranoy, I, pp. 152-153 y 162-163, II, pp. 102-103 y 111. Por cierto, una propuesta de localización del primer enfrentamiento se encuentra en: Erkoreka [Barrena], "A furore normanorum", p. 22.

26 González Paz, O bispado de Mondoñedo, pp. 182-184.

27 El desplazamiento se cuantifica entre los 0,5 y 2 kilómetros en los ejemplos documentados.

28 Mapa Topográfico Nacional 1:50.000 (MTN50). $1^{\text {a }}$ ed. Cartografía C Instituto Geográfico Nacional de España. PNOA cedido por (C) Instituto Geográfico Nacional de España. 


\section{Las unidades de ocupación y estructuración del paisaje histórico local en la Alta y Plena Edad Media (siglos X-XII)}

Tras un hiato de varios siglos de oscuridad informativa -ocasionado por la ausencia de testimonios escritos y materiales-, el cartulario monástico de San Salvador de Lourenzá (Lourenzá, Lugo) nos muestra la existencia a la altura de la segunda mitad del siglo X de la villa de Superato de Burela, núcleo de ocupación, población y producción situado en la falda de una elevación montañosa conocida como montem Aquilare ${ }^{29}$, entre los arroyos Torrentes y Pumeda, y localizado a menos de un kilómetro de distancia (en línea recta) del asentamiento romano de O Campón.

Esa referencia documental a la primitiva villa de Burela-obviamente escueta, pero significativa- se encuentra en la noticia de la extensa hacienda que el $d u x$ Gutier Osóriz ${ }^{30}$-hijo del conde Osorio Gutiérrez, fundador del monasterio- habría donado a la comunidad monacal entre finales del siglo $\mathrm{X}$ y principios del siglo $\mathrm{XI}^{31}$. Su laconismo no resulta óbice en el reconocimiento de dos cuestiones de interés respecto de la villa burelense: aún ignorándose sus orígenes materiales y temporales concretos, su realidad efectiva a esa altura temporal y, aún desconociéndose el mecanismo jurídico de adquisición, su integración previa en el patrimonio aristocrático de los Osóriz, desde el cual revierte en el dominio del cenobio familiar como fruto de la liberalidad del magnate laurentino ${ }^{32}$.

Actualmente, ante la inexistencia de datos arqueológicos o documentales específicos, no es posible reconstruir con precisión los elementos constituyentes de la villa de Superato de Burela. Ante el silencio de la arqueología, resultaría factible acudir a la tradición historiográfica y atribuir a este asentamiento una serie de características internas y externas que, a buen seguro, se aproximarían -cuando menos de manera

29 El 21 de agosto de 1096 el conde Raimundo de Borgoña y su esposa, la infanta Urraca de Castilla, entregaban al obispo Gonzalo Froilaz [de Traba] y a la sede dumiense-mindoniense la mitad de la iglesia de San Xiao de Nois (Foz, Lugo), especificándose que habet iacentiam litore maris inter Burellum et Aurium subtus montem Aquilare et Faro. Cal Pardo, Colección diplomática medieval, doc. 9, pp. 22-23. En la actualidad, el montem Aquilare se conoce oficial y localmente como Monte Castelo, significativo orónimo cuyo empleo se registra desde el siglo XIX. Madoz [Ibáñez], Diccionario, IV, p. 502. Sin embargo, por ejemplo, en las respuestas generales del Catastro de Ensenada correspondientes a la feligresía de Santa María de Burela (16/12/1752) se denomina "Castelo das Eiras". Archivo General de Simancas (en adelante AGS), Catastro de Ensenada (en adelante CE), Respuestas Generales (en adelante RG), 1. 206, f. 341v. Por otra parte, la primera referencia documentada del monte Faro se adelantaría al 5 de julio de 1077, cuando García Eníguiz intercambiaba ciertos bienes radicados en la uilla uocitata Marçani (Foz, Lugo) con el monasterio de Vilanova de Lourenzá, explicándose que se hallaba suptus monte Faro, prope aulam Beati Martini episcopi dumiensis sedis, discurrente ad ecclesia Sancti Iacobi, ripa Masme. Rodríguez González y Rey Caiña, “Tumbo de Lorenzana”, doc. 81, pp. 119-120. Aún a mediados del siglo XVIII, el "Pico de Faro" se señala como hito de delimitación del término parroquial de San Pedro de Cangas (Foz, Lugo). AGS, CE, RG, 1. 206, f. 422r.

30 Con respecto a este magnate -de existencia documentada entre los años 952 y 999 y que seguramente falleció a comienzos del siglo XI-, y en general, sobre el grupo magnaticio Osóriz y su relevancia en el entramado del reino astur-leonés, pueden consultarse: Sáez [Sánchez], "Los ascendientes de San Rosendo", pp. 3-75 y 179233. Carro Otero y Varela Ogando, "Estudio anatonomo-antropológico”, pp. 79-114. Torres Sevilla-Quiñones de León, Linajes nobiliarios, pp. 299-300 y 307-311. Andrade Cernadas, "O “conde santo" Osorio Gutiérrez", pp. 315-324. González Paz, Osorio Gutiérrez.

31 "Tumbo de Lorenzana", doc. 13C, pp. 43-45. De esta forma seguía la senda paterna, ya que el conde Osorio Gutiérrez había concedido un extenso patrimonio fundiario a la comunidad monacal laurentina el 17 de junio de 969, asistiendo sus hijos Gutier y Ordoño Osóriz. Ibidem, docs. 1-2, p. 25.

32 Ningún elemento señalado desentonaría en las coordenadas del binomio época/territorio y el ámbito de los monasterios de fundación familiar magnaticia: Portela Silva y Pallares Méndez, "Os mosteiros", pp. 51-71, especialmente 52-59. 
relativa- a su realidad morfológica ${ }^{33}$. Sin embargo, en esta ocasión se recurrirá a la aplicación del procedimiento analógico, empleándose como fuente de información varios casos registrados en coordenadas geográficas y temporales semejantes.

De resultas de ese análisis, se infiere que la villa sería una entidad de población -al unísono, un lugar de residencia y un centro de explotación del medio naturalheterogénea ${ }^{34}$, configurada en diferentes áreas funcionales de ocupación antrópica y niveles de transformación antropogénica ${ }^{35}$, de extensión y dimensiones variables, que mantendría una relación multiforme con el litoral -desde marco de referencia espacial $^{36}$ a fuente de recursos económicos ${ }^{37}$ - en un ecosistema productivo mixto de carácter agropecuario y marino.

Con todo, esta célula básica de la organización socioeconómica del territorio no era una isla en el hábitat altomedieval de este sector costero cantábrico gallego pues, según se desprende de la lectura del apeo patrimonial laurentino, el escenario se

33 Sobre el concepto y la semántica de villa en esta época, debe señalarse la existencia de cierta tradición entre el medievalismo gallego, destacándose a continuación dos obras caracterizadoras de dos momentos concretos: Pallares Méndez y Portela Silva, "Aproximación al estudio de las explotaciones agrarias", pp. 95-113, especialmente 99-108. Baliñas Pérez, Do mito á realidade, pp. 209-230. Otros referentes serían: Pallares [Méndez] y Portela [Silva], "De la villa del siglo IX a la aldea del siglo XIII", pp. 47-69. Baliñas Pérez, Gallegos del año mil, pp. 111-135. Portela [Silva] y Pallares [Méndez], "La villa, por dentro", pp. 13-43. Pallares [Méndez] y Portela [Silva], "El lugar de los campesinos", pp. 61-87. Por último, entre las síntesis más recientes se encontraría: López Sabatel, "La villa altomedieval gallega", pp. 78-100.

34 Sin duda, esa heterogeneidad se comprueba en factores como la denominación, titularidad y caracterización cuando se observan, por ejemplo, la dotación testamentaria del conde Osorio Gutiérrez o la extensa noticia de villas de Guterri Osoriz que dedit monasterio Villenoue. "Tumbo de Lorenzana”, docs. 1-2 y 13C, pp. 21-26 y 43-45.

35 Como se observaría, por ejemplo, en el caso de la villa de Marzán (Santiago de Foz, Foz, Lugo). Así, el 31 de agosto de 1015 Guntina vendía la uilla que uocitant Marzam, locum predictum ipso casale ubi ipsos meos parentes habitauerunt, Estofredo et Cognomia. Do tibi ipso casale et ipsa cortina sub ipso casale -es decir, el casal y su huerta- ab integro cum omnia sua prestancia, así como terras et pumares, arbores fructuosas et infructuosas, petras mobiles et inmobiles, bouzas, montes, fontes, accessu uel recessu in ipsa uilla de Marzany. Dos años más tarde, concretamente el 1 de noviembre de 1017, Vega y su nieto Vermudo entregaban de casale nostro proprio quod habemus in uilla Marçan, locum predictum inter casa ubi nos habitamus et de casa de Froyla Citiz, ipso casale quod dicent Uiciar, medietate de ipso casale et de ipsas parietes et terra calua que est aretore ipso casale, de parte occidentale per illa seara et propre de illa arena usque illo uallo et de parte orietale per termino de terra de ipse Froyla Uitiz per alia usque agro quod tibi dedi ipse Froyla. Damus tibi ipso casale cum suo exitu et cum suos ortales in toto per suo termino. Por su parte, el 5 de julio de 1077 García Eníguiz permutaba, de la uilla uocitata Marçani, casales cum suos solidos, quinta de Froyla Garsia et quinta de Gundisaluo Garsia et quinta de Acenar Garsia et tercia de quinta de Enego Garsia. Id est, do uobis in ipsa uilla terras cultas uel incultas, petras mobiles uel fictiles, arbores fructuosas uel infructuosas, montes, fontes, platis, pascuis, paludibus, existus moncium et regressus, aquis aquarum cum eductibus suis. Ibidem, docs. 51 y 80-81, pp. 87-88 y 118-120. Sobre el casal y su compleja semántica, véanse: Ríos Rodríguez, "El casal medieval gallego", pp. 109-128. Marques, O casal.

36 E1 22 de julio de 927 el confessus Egica concedía la uilla que uocitant Masma secus littora maris ubi habitauit auus meus Ermemirus a domno Gutier et domna Ilduncia. A su vez, el 8 de junio de 1089 Gutier Osóriz donaba una villa in territorio Uille Plane, id est, Uilla Uoliz, discurrente ad ecclesiam Sancte Eulalie, prope litus maris. "Tumbo de Lorenzana", docs. 124 y 195, pp. 162-163 y 247. La segunda entidad se correspondería con el lugar de Vilagoíz (Santalla da Devesa, Ribadeo, Lugo), ubicado a 1,5 kilómetros de la actual línea de costa.

37 En ese sentido, por ejemplo, el 18 de julio de 916 el rey Ordoño II otorgaba a la sede dumiense-mindoniense la uillam nomine Uaris (A Vila de Bares, Santa María de Bares, Mañón, A Coruña) cum familia sibi pertinenti per terminum de aqua de ectario et inde per montem dominicum ast per pennam Iuliani et per Montarion usque ad illum portum de Delfino atque Sauris siue ostrarias uel diuesas seu piscarias. Cal Pardo, Colección diplomática medieval, doc. 2, pp. 12-13. Asimismo, el 3 de marzo de 1078 el monasterio laurentino recibía la villa que uocitant Pumar Ruiino, situada in territorio inter Euue et Masma, discurrente ad ecclesia Sancti Michaelis (Pumarrubín, San Miguel de Reinante, Barreiros, Lugo), con sus solares, casas coopertas uel incoopertas, petras mobiles uel inmobiles, arbores fructuosas uel infructuosas, terras cultas uel incultas, aquas aquarum et sessigas molinarum cum eductibus aquarum earum, siue portum maris, piscarium, siue sessicas salinarum cum eductibus lignarum. "Tumbo de Lorenzana", doc. 53, pp. 90-91. 
completaba con la presencia de una fortificación en sus aledaños, llamada castello Aquilar $^{38}$, denominación deudora del orónimo anteriormente señalado.

En el marco de una taxonomía tipológica determinada ${ }^{39}$, ese castello se adscribiría a la categoría de "fortificaciones en altura" ${ }^{40}$, cuyos rasgos caracterizadores serían su localización en emplazamientos (normalmente afloramientos rocosos) seleccionados debido a su elevada potencialidad defensiva - en los cuales las significativas condiciones de defensa natural se incrementaban con defensas antrópicas-, dotados de una destacada altura relativa respecto al medio de referencia -lográndose así un amplio dominio visual-, en las que solía primar su utilidad como refugio temporal ante ataques, así como elementos de control y vigilancia del espacio terrestre o marítimo.

¿Cuál sería la razón y función concreta del castello Aquilar? Seguramente, la respuesta a esta doble cuestión se deba vincular de nuevo con su ubicación costera, con su cercanía al mar, fuente de dos graves amenazas para las entidades, poblaciones e instituciones ribereñas: en un primer momento, coincidiendo precisamente con la cronología altomedieval del testimonio, las incursiones normandas ${ }^{41} \mathrm{y}$, en un segundo período plenomedieval, las razias musulmanas ${ }^{42}$.

Sin embargo, cabe preguntarse si la defensa de los habitantes de este espacio sería el único propósito de esta fortificación en altura o si, al contrario, en el castello Aquilar se agregarían otras finalidades. En las coordenadas históricas del testimonio,

38 Esta denominación no resulta extraña en la mitad oriental del territorio gallego altomedieval. Así, entre otros ejemplos, se testimonian Aguiar (Castro de Rei, Lugo), Aguiar da Moa (Os Blancos, Ourense), Aguiar de Pedraio (Nogueira de Ramuín, Ourense), Aguiar (Sobrado, León) y más tardíamente, en otro contexto, Sobrada de Aguiar (Outeiro de Rei, Lugo).

39 Esta propuesta de clasificación -inevitablemente dotada de cierto grado de artificialidad y discrecionalidad, mas siempre abierta a discusión- fue presentada y argumentada en: González Paz, La arquitectura militar medieval, pp. 48-83. Trabajo de Investigación Tutelado realizado bajo la dirección académica del Prof. Dr. Carlos Baliñas Pérez.

40 La semántica atribuida a esta expresión se inspira, sobre todo, en el contenido de los trabajos de Gutiérrez González. Entre otras obras, se podrían relacionar: Fortificaciones y feudalismo. Peñaferruz (Gijón). "Castillos y fortalezas feudales", pp. 5-36, "Castillos y fortificaciones feudales", pp. 493-517, ambos con Suárez Manjón. Sin duda, ese concepto aplicado a ese tipo de fortificaciones ha logrado cierto predicamento entre un sector de la historiografía centrada en el estudio de la arquitectura y arqueología militar medieval. Así, por ejemplo, en el caso gallego se constata en: González Paz, "Fortificaciones medievales", pp. 585-629, "Catro exemplos de fortificacións", pp. 359-368. Sánchez Pardo, "Castros, castillos y otras fortificaciones", pp. 29-55; "Fortificaciones de altura", pp. 125-161, con Galbán Malagón.

${ }^{41}$ Véase, con respecto a este asunto, Ferreiro Alemparte, Arribadas de normandos y cruzados, pp. 25-59. Sánchez Pardo, "Los ataques vikingos", pp. 60-75. Christys, Vikings in the South. Sin duda, entre los testimonios conservados merece destacarse el pactum uel placitum que varios abbates, presbyteros, laicos, monachos e infançones habrían acordado con el obispo Hermenegildo de Lugo el 1 de noviembre de [968], en cuyos términos se establecía que ueniamus omnes strenue ad ipsam ciuitatem ad habitandum et faciamus nostras casas, in quo reponamus nostrum ganatum et nostrum atonitum et simas ibidem habitantes et dimicantes contra seuientem gentem lothmanorum. López Sangil y Vidán Torreira, “Tumbo Viejo de Lugo”, doc. 82, pp. 175-176.

42 Sobre ataques sarracenos ocurridos en la primera mitad del siglo XII, que podrían haber afectado al área de estudio, en la Historia Compostellana se indica que: Hisdem temporibus Hispalenses, Saltenses, Castellenses, Siluenses, Lisbonenses ceterique Sarraceni ab Hispali usque ad Colimbriam confinia maris incolentes naues construere consueuerant, et nauigio armata manu uenientes maritima a Colimbria usque ad Pirenaeos, uidelicet Portugalliam, Morracios, Saliniensium fines, Pistomarchos, Gentines, Nemancos, Sonariam, Salagiam, Bregantinos, Nemitos, Prucios, Bisancos, Trasancos, Viuariam, Ourios, Nauiam, ceterosque maritimos Asturum fines terramque sancte Iuliane depopulando uastabant. Historia Compostellana, lib. I, cap. CIII, Falque Rey, p. 174. Precisamente, entre la argumentación a la que se habría recurrido al solicitar el traslado de la sede episcopal desde el loco minduniensis (San Martiño de Mondoñedo) al uallibriensi loco (Mondoñedo), se habría aducido su proximidad al mar y su indefensión frente a las razias musulmanas: Sicut enim ex litteris vestris comperimus prior Ecclesia in littore maris solitarie posita, \& absque ulla munitione Mohabitarum navigio, \& tyrannorum oppressionibus pervia, adeo desolata erat, ut in ea vix manere quis posset. Flórez, España Sagrada, XVIII, doc. XIX (adición), pp. 339-340. 
no debería excluirse apriorísticamente esa posibilidad, siendo acaso empleado como instrumento articulador del territorio circundante, en una relación generadora de sinergias y dependencias ${ }^{43}$.

En el transcurso del siglo XII, en el contexto de una etapa de crecimiento y desarrollo en tierras mindonienses, se atestiguan dos nuevos estadios en la evolución de la villa de Burela. Por una parte, se constata la existencia de la iglesia de sancta Maria de Burela ${ }^{44}$-cuyas rentas se asociaban coyuntural y temporalmente al patrimonio regio en 1124, destinándose a los levantiscos comites cum karactere regis-.

Lamentablemente, en este momento se desconocen varios elementos significativos asociados a su trayectoria histórica como son sus orígenes - una nueva asignatura pendiente de la arqueología medieval-, su fecha de fundación, su ubicación-aunque resulte altamente probable su emplazamiento en el solar que ocupará posteriormente el templo tardomedieval, carecemos de testimonios materiales precisos que lo corroboren- $\mathrm{o}$, finalmente, si a la altura del primer cuarto de la duodécima centuria, sería ya una auténtica iglesia parroquial destinada a la atención espiritual y práctica sacramental de una feligresía territorializada ${ }^{45}$.

Por otra parte, se comprueba la presencia del "villar de Burela", una nueva célula de habitación y producción en el entramado territorial burelense ${ }^{46}$. En $1164 \mathrm{Pe}-$ dro Guimáraz otorgaba a la comunidad monástica de Santa María de Meira (Lugo) su quiñón de las "heredades que tenía en Viuero çerca del mar, que son las villas d'Espiñareda y la Rúa de Fontao y el villar de Burela y Salgadelos"47.

Aunque se ignoran las características concretas de este villar, ciertos factores, como su identidad toponímica y su localización en el sector septentrional de la vaguada que conforma el arroyo de Pumeda, podrían sugerir un vínculo directo con la villa de Burela, siendo el resultante de un proceso endógeno de ocupación y explotación del espacio suburbial. Simultáneamente, su referencia individualizada y titularidad fragmentada podrían ser síntomas de la autonomía alcanzada a esta altura temporal.

En el transcurso de prácticamente dos siglos de trayectoria histórica, la configuración del espacio de este sector central del litoral cantábrico gallego se vio modificada de manera substancial como consecuencia de la intensa actividad antrópica que, a la altura de la segunda mitad del siglo XII, se manifestaba materialmente -y se articulaba, estructuraba, ordenaba u organizaba- a través de cuatro unidades básicas - villa, castello, ecclesia y villar (en orden cronológico de testimonios)- en un contexto social y económico claramente expansivo.

43 En ese sentido, desde finales del siglo XI, la documentación ofrece una serie creciente de indicios relativos a la existencia de una circunscripción territorial de naturaleza supralocal -denominada Burellum o Burella, asistiéndose así a la identificación de corónimo y topónimo-, que se extendería a levante y poniente de Torrentes -hidrónimo aún conservado en la microtoponimia del actual aglomerado burelense-. Cal Pardo, Colección diplomática medieval, docs. 9 y 11, pp. 22-23 y 24-27. "Tumbo de Lorenzana”, doc. 215, pp. 266-267. Tal vez se tratase del precedente -acaso germen- del "coto de Burela", jurisdicción tardomedieval que el 10 de marzo de 1593 se incorporaba a la corona hispana. Cal Pardo, Episcopologio Mindoniense, pp. 377-378.

44 Cal Pardo, Colección diplomática medieval, doc. 11, p. 26.

45 Probablemente, la respuesta a esta cuestión debiese ser positiva mas, ante la ausencia de datos irrefutables considerándose inconcluyente el empleo ocasional del término felegresia en el texto (idem)-, una afirmación taxativa resultaría aventurada.

46 Sobre el concepto y la semántica del término "villar", véanse: Pallares Méndez y Portela Silva, "Aproximación al estudio de las explotaciones agrarias”, pp. 108-110. Baliñas Pérez, Do mito á realidade, pp. 221-222.

47 Archivo Histórico Nacional (en adelante AHN), Códices, 1. 114, f. 395v. Espiñeirido y A Rueta/Fontao, en Santa María de Cervo, y Vilar, en San Román de Vilaestrofe, topónimos correspondientes al actual término municipal de Cervo (Lugo). 
Ciertamente, entre las lecturas factibles de esas células territoriales, resulta de interés su titularidad y, fruto de diferentes dinámicas, la constitución de Burella en un tablero de ajedrez imperfecto, en el cual se constata la coexistencia de elementos pertenecientes a dominios laicos $\mathrm{y}$, de forma creciente, eclesiásticos (monásticos y diocesanos). Sin embargo, ese panorama general se irá modificando significativamente en las centurias siguientes, adquiriendo un mayor protagonismo, de forma gradual, el factor señorial laico que, en unas nuevas coordenadas históricas, empleará la "Suçesion de Burela" como instrumento de acceso y control.

Figura 5. Castello Aquilar ${ }^{48}$.
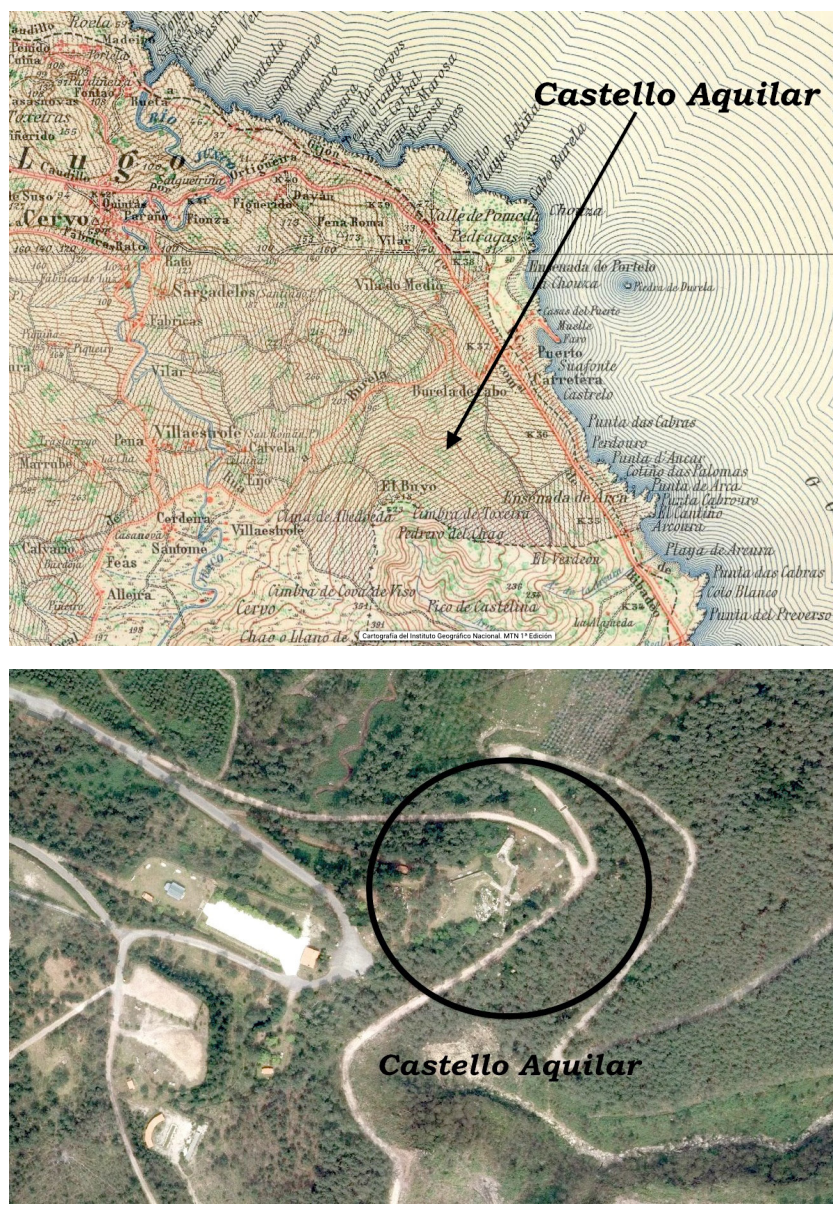

48 Mapa Topográfico Nacional 1:50.000 (MTN50). $1^{\text {a }}$ ed. Cartografía C Instituto Geográfico Nacional de España. PNOA cedido por (C) Instituto Geográfico Nacional de España. 


\section{La "Suçesion de Burela": señorialización laica y patrimonialización territo- rial (siglos XIII-XV)}

Los orígenes del conjunto patrimonial conocido como "Sucesión de Burela" se remontan a mediados del siglo XIII, surgiendo como resultado de la reunión de los legados que Pedro Pérez, arcediano de Azúmara, y García Pérez, canónigo, habían otorgado a la iglesia mindoniense. Los bienes constituyentes de esta hacienda se hallaban relativamente dispersos en la franja litoral del septentrión lucense, situándose concretamente, de este a oeste, in villa Aldriz, in Cinge, in villa Armea, in ecclesia de Burela, in ecclesia de Ceruo, in ecclesia de Lieyro, in ecclesia de Cellario ${ }^{49}$.

El acto de disposición de este patrimonio más tempranamente documentado acaso el primero realizado- se llevaba a cabo el 17 de octubre de 1258. A instancias del obispo Juan II Sebastianes (1248-1261), se aforaba al chantre Rodrigo García -hermano de Pedro García, arcediano de Viveiro-, atribuyéndose carácter transmisible a la aludida concesión. Después de su fallecimiento, la sucesión en la posesión continuaría en sus hermanos Fernando García y Marina García de Trasbar et filiis et nepotibus suis de legitimo matrimonio procreatis, estableciéndose como condiciones que unus de parentela sua qui fuerit maior etate et honore semper sit principalis dominus et heres, et fructus diuidat equaliter cum aliis consanguineis suis ${ }^{50}$.

Efectivamente, Marina García de Trasbar, Fernando García y, tras su muerte, sus hijas Mayor Fernández - esposa de Juan Martínez, alcalde de Viveiro- y Teresa Fernández -mujer de Pedro Fanego- usufructuaron esos bienes durante más de treinta años. Sin embargo, a finales del siglo XIII y ante la virtualidad de su enajenación, el cabildo mindoniense forzó la realización de un segundo convenio. Firmado el 4 de diciembre de 1293, en su clausulado se refrendan y renuevan las estipulaciones del aforamiento, determinándose el momento de extinción de la relación y reversión del patrimonio "liuremente et en pas aa eglesia de Mendonnedo" 51 .

El reintegro del conjunto de heredades al patrimonio de la sede mindoniense debió acontecer en el transcurso de la primera mitad del siglo XIV, ya que el 3 de mayo de 1352 se lleva a cabo -o al menos se intenta- una nueva concesión foral, cuyos beneficiarios fueron "Pedro Fernandes et a uossa muller Aldara Peres" y "Lopo Fernandes et a uossa muller Mayor Eanes", ambos "fillos de Fernan Basanta et de sua mulleer Tereyia Martines", transmisible dos generaciones más a través de "fillos baroes legitimos", después de lo cual "deuen a ficar liuremente desenbargadas de uossa uos et deles ao cabidoo da iglesia de Mendonnedo" 52 .

49 En la actualidad Vilandriz y Cinxe, Santalla da Devesa (Ribadeo, Lugo); Vilarmea, Santiago de Fazouro (Foz, Lugo); Santa María de Burela (Burela, Lugo); Santa María de Cervo y Santa María de Lieiro (Cervo, Lugo) y Santiago de Celeiro (Viveiro, Lugo).

50 Cal Pardo, Calendarios, doc. 78, p. 29. Seis años más tarde, el chantre mindoniense redondeaba sus posesiones en la zona central de la costa lucense. Así, el 31 de marzo de 1264 el magnate Juan Pérez, fillius domni Pedri Poncii et domne Eldonncie Alffonsi, pignoraba a Roderico Garssie cantori ecclesie mindoniensis illas partes ecclesiarum quas de me tenuistis et tenetis in prestimonio vsque modo videlicet medietatem vnius octaue ecclesie Sancte Marie de Çeruo, quintam partem Sancte Marie de Lieyro, et quartam partem ecclesie Sancti Saluatoris de Ioue. Cal Pardo, Tumbo Pechado, doc. 190, pp. 180-181.

51 Cal Pardo, Calendarios, doc. 359, p. 92. Por cierto, alrededor del año 1382, se revisaban los documentos custodiados en el arca del cabildo mindoniense, mencionándose una "carta da subçeson do chantre don Ruy Garçia et deuen de pagar cada anno o foro en vespera de Santa Maria dagosto et por kalendas janeyras et por Pasqoa et se o asy non feseren deuen a perder a suçeson et hase de tornar ao cabidoo". Ibidem, doc. 1062, pp. 455-456.

52 Ibidem, doc. 941, pp. 362-363. En esta escritura de foro, se refiere en tres ocasiones "outra carta que 
Desde una doble perspectiva patrimonial y territorial, esa entrega incluía "as nossas herdades que nos auemos Vilarmea enna fiigresia de Fasouro et en Çinge et en Vilaldris que son enno alfos de Ribadeu" más "os padroados que nos auemos enna quarta parte da iglesia de Santiago de Çeleiro sen cura que he en termino de Viueyro et enna meatade da iglesia de Santa Maria de Lieyro con cura et ennas duas partes da iglesia de Santa Maria de Ceruo sen cura et enna meatade da iglesia de Santa Maria de Burela sen cura".

Por su parte, desde la óptica de las relaciones señoriales, las autoridades eclesiásticas mindonienses -con el obispo Alfonso Sánchez [de Moscoso] (1347-1366) a la cabeza- deseaban recompensar "que foron fostes senpre et sodes a seruiço do bispo et da iglesia de Mendonnedo et o uosso linagen et lle fostes senpre obidientes"

Tras medio siglo de silencio de las fuentes, la "Sucesión de Burela" regresa a la documentación mindoniense en los últimos compases de la decimocuarta centuria, vinculada al escudero Fernán Cao de Cordido ${ }^{54}$, receptor del aforamiento de la "suçeson" -así como de las "herdades de Lieiro et de Çeruo et de Lago" fallecimiento, retornó al control del cabildo de Mondoñedo.

Sin embargo, esa situación duró escaso tiempo pues, en una coyuntura favorable de recuperación y reactivación productiva ${ }^{56}$, las instituciones señoriales se muestran activas en la cesión de bienes, derechos y tierras a terceros, buscándose una rentabilización económica y social de sus patrimonios. Así, el 12 de septiembre de 1402, a instancias del obispo Álvaro Núñez de Isorna (1399-1415), se aforaba a Ares Vázquez, "fillo de Ares Vasques de Vaamunde", la "susçeson que Fernan Cao de Cordido soya teer rendada" 57 .

Nueve años más tarde, el 25 de mayo de 1411, el cabildo mindoniense realizaba una nueva concesión foral, en esta ocasión a favor de Ares Vázquez de Vaamonde, "escudeyro do bispo de Mendonnedo fillo de Martin Vasques de Vaamonde", que recibía

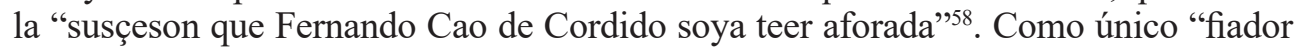
deuedor et prinçipal pagador" se señala a su hermano Pedro Ares de Vaamonde, entonces arcediano de Viveiro, que alcanzó con posterioridad el deanato de Ourense y la cátedra episcopal de Mondoñedo (1446-1448) ${ }^{59}$.

connosco auedes sobre estas herdades sobreditas que he escripta enno liuro do cabidoo desta iglesia". ¿Se trataría este segundo texto de un complemento, modificación o ampliación de los términos del aforamiento? Lamentablemente, no se ha localizado ese primer documento, resultando imposible ofrecer una respuesta fidedigna a esa cuestión.

53 En este sentido, guardaría semejanza con la terraria compostelana: González Vázquez, El arzobispo de Santiago, pp. 154-175.

54 Cal Pardo, Tumbo Pechado, doc. 92, p. 97.

55 Ibidem, doc. 36, p. 50. Con respecto al último bloque patrimonial, en la segunda mitad del siglo XIV se testimonia una sucesión de negocios jurídicos. Así, el 20 de julio de 1365 el cabildo mindoniense aforaba a Rodrigo Álvarez de Santiago, clérigo de Santa María de Galdo (Viveiro), las heredades situadas "enna frigesia de Santaoalla de Lago", "enna frigesia de Santa Maria de Lieyro" y "enna frigesia de Çeruo". Nueve años más tarde, concretamente el 11 de febrero de 1374, Rodrigo Álvarez -"coengo de Santiago et de Mendonnedo"traspasaba a Fernán Cao de Cordido -"escudeyro criado do arçebispo de Santiago don Rodrigo"- el aforamiento de los "herdamentos casas et chantados et dereyturas da frigesias de Santa Maria de Çeruo et de Santa Maria de Lieyro et de Santaoalla de Lago hu quer que foren a montes et a fontes et nas marinas de Viueyro et de Sancibrao". Finalmente, el 11 de diciembre de 1402 Juan Cao de Cordido -"conpridor herdeyro que ficou de Fernan Cao seu tio"- solicitó y logró del cabildo de Mondoñedo su subrogación en el foro de estos bienes. Ibidem, doc. 11, pp. 19-20.

56 Rodríguez Galdo, Señores y campesinos, pp. 36-37.

57 Cal Pardo, Tumbo Pechado, doc. 213, p. 196.

58 Ibidem, doc. 497, pp. 472-473.

59 Ibidem, doc. 275, p. 246. Siendo aún “dean d-Ourense et arçediano de Viueyro” instituyó la celebración de 
Con ese acto jurídico, se iniciaba un largo proceso de patrimonialización, que rematará con la apropiación señorial de los bienes integrados en la "Sucesión de Burela". Según se establece en el documento de formalización, el aforamiento era vitalicio y transmisible mortis causa, de forma sucesiva, a "outras duas pesoas quaes el diser et nomear depoys de sua morte en seu testamento et non fasendo el testamento ou non nomeando aquelas pesoas que aquel que herdar a mayor parte dos seus bees que o aja" ${ }^{\circ 0}$.

Tras el fallecimiento del escudero Ares Vázquez de Vaamonde, la sucesión continuó en su hija, Mayor Martínez de Vaamonde ${ }^{61}$-casada con Fernán Díaz de Ribadeneira-, y su nieto, Martín Vázquez de Vaamonde ${ }^{62}$, canónigo mindoniense, cuya defunción aconteció entre 1480 y $1481^{63}$. De esta forma, aparentemente se habrían perfeccionado los términos temporales del foro, extinguiéndose la relación contractual y, como consecuencia de este hecho, se activaría la obligación de la reversión del patrimonio al cabildo de Mondoñedo ${ }^{64}$.

Sin embargo, los bienes no regresaron a las arcas capitulares, sino al contrario, se integraron en la hacienda de Pedro Fernández de Bolaño, asimismo vástago y heredero de Fernán Díaz de Ribadeneira y Mayor Martínez de Vaamonde, que estaba casado con Beatriz de Castro, hija del mariscal Pedro Pardo de Cela y de Isabel de

una misa de aniversario que debía sufragar el cabildo mindoniense o, en su defecto, "aquel que for sennor et teuer a casa de Vaamonde". Ibidem, doc. 2, p. 11. Sobre el grado de parentesco existente entre receptor y fiador, pueden consultarse las siguientes referencias: López Ferreiro, Historia, VII, p. 139. Pardo de Guevara y Valdés, "Parentesco y nepotismo", p. 91, n. 116. Con respecto al linaje Vaamonde, resultan de interés los apuntes genealógicos incluidos en: Saavedra Rivadeneyra y Aguiar Pardo de Figueroa, Memorial de la Casa de Saavedra, f. $16 \mathrm{r}$.

60 Cal Pardo, Tumbo Pechado, doc. 497, p. 473.

${ }^{61}$ La sucesión foral ocurrió antes del 27 de julio de 1451. En esta fecha se informa de que Mayor Martínez no había abonado las "aniuersarias de Burela" al clérigo Juan Amor. Al año siguiente, concretamente el 15 de julio de 1452, se reitera la existencia de la deuda del "foro de Burela". Cal Pardo, Mondoñedo -catedral, cidade, bispado-, docs. 3 y 6, pp. 16-17 y 22-23. En su condición de "persona et leuador que era do foro et suçeson" capitular, se testimonia administrando o recibiendo los beneficios de esos bienes eclesiásticos. Así, el 28 de agosto de 1458 Vasco Rodríguez de Vilarmea mostraba al cabildo una carta de foro que había realizado "donna Mayor sennora de Vaamonde muller de Fernando Dias de Ribadeneyra" de "huna cortynna de herdade con sua pumarega que jas enno fondal dela que he da dita suçeson et jas enno lugar de Vilarmea onde dizan a Hermida commo se departe da huna parte do camino françes que sal do couto de San Martinno et vay para a ponte de Fazouro". Cal Pardo, Tumbo Pechado, doc. 309, pp. 277-278. Por su parte, el 20 de noviembre de 1466, los canónigos mindonienses llevaban a cabo una "carta de aforamento et contrauto infiteotico" a favor de "Johan Aluares de Vylafane escripbano de noso sennor el rey et a vosa muller Veatris Vasques de Vaamonde vesinos et moradores enna vila de Ribadeu", cuyo objeto eran varias heredades situadas "en las aldeas de Çinge et Sisto et sus terminos segund que las lebaua de nos la sennora donna Mayor de Vaamonde su el signo de la iglesia de Santaalla da Deuesa las quales ditas herdades brabas et mansas que son de la suçeson de Burela que leba la dicha sennora donna Mayor de Vaamonde de los sennores dean et cabildo de la dicha iglesia de Mondonnedo". Cal Pardo, Mondoñedo-catedral, cidade, bispado-, doc. 48, pp. 86-88. Además, a la muerte de su padre, se situó al frente del grupo y patrimonio familiar, ambos representados en la casa solar. Así, Alfonso López de Gaibor atestiguaba en el pleito Tabera-Fonseca que la hermandad había derrocado la "fortaleza de Baamonde que hera de doña Maior de Baamonde”. Rodríguez González, Las fortalezas de la mitra compostelana, II, p. 487. Por cierto, esa fortificación lucense habría sido construida en vida de Martín Vázquez de Vaamonde. Pardo de Guevara y Valdés, "Vellas e novas liñaxes", p. 280, n. 34.

62 El 24 de octubre de 1470 compareció "Martin Vasques de Vaamonde fillo de donna Mayor de Vaamonde muller que foy de Ferrnand Dias de Ribadeneyra" ante el cabildo mindoniense, mostrando una serie de poderes que habían otorgado sus hermanos, concediéndole la continuación en la "suçesion de Burela". Los canónigos aceptaron la decisión y mantuvieron las estipulaciones de este "foro et subçesion". Cal Pardo, Mondoñedo catedral, cidade, bispado-, doc. 62, pp. 103-104.

63 E1 20 de agosto de 1481 Pedro Fernández de Viveiro “cardenal enna santa iglesia de Santiago" asumía la canonjía mindoniense que había quedado vacante "por morte et fyn et deçeso del onrrado Martin Vasques de Vaamonde". Ibidem, doc. 221, pp. 311-312.

64 Cal Pardo, Colección diplomática medieval, doc. 202A, pp. 405-413. 
Castro $^{65}$. Este acontecimiento llevó a las autoridades catedralicias mindonienses a reclamar judicialmente la devolución del conjunto patrimonial de la "Suçesion de Burela" 66 .

El 30 de octubre de 1482 García de la Parra, alcalde mayor en el obispado de Mondoñedo a nombramiento del "sennor don Ferrnando d-Acunna justiçia mayor en este reyno de Galizia", sentenciaba contra los intereses del "sennor et honrrado caballero Pedro de Volanno", a quien se ordenaba reintegrar los bienes y rentas usurpados al deán y cabildo de Mondoñedo ${ }^{67}$. Frente a esta resolución desfavorable, Pedro Fernández de Bolaño siguió dos caminos: conserva la posesión efectiva del patrimonio, mientras apela a una instancia judicial superior.

Ante los oidores de la audiencia vallisoletana, los procuradores del magnate lucense alegaron que el período de administración de su hermano Martín Vázquez de Vaamonde no debería ser contabilizado como segunda "persona del fuero", ya que esa posición correspondía a su representado como "fijo primogenito mayor" de Mayor Martínez de Vaamonde. Con todo, las autoridades judiciales no consideraron válidos sus argumentos, ni fiables sus probanzas, y confirmaron el veredicto de García de la Parra, como consta en la sentencia de revista de 15 de octubre de $1484^{68}$.

Después de tres años de litigio, el caballero Pedro Fernández de Bolaño observaba cómo se cerraba la vía judicial con un serio revés a sus intereses, al mismo tiempo que comprobaba cómo el cabildo de Mondoñedo demandaba la ejecución del dictamen de la chancillería. En ese sentido, el 5 de febrero de 1485 el gobernador Diego López de Haro ordenaba a Fernán Pérez de Gijón, corregidor de Mondoñedo, y Fernando Cerón, corregidor de Viveiro, que cumpliesen con el contenido de la sentencia y apoderasen a los canónigos mindonienses en la posesión de la "Suçesion de Burela"

Finalmente, en la segunda quincena de marzo de 1485, el alguacil Alonso de Astudillo acompañaba a Ruy Basanta y Ảlvaro de Marco, representantes capitulares, otorgándoles la posesión de los bienes, frutos, rentas y beneficios vinculados a la "suçesion". El periplo se iniciaba en la "feligresia de Santaalla" y proseguía en las "feligresias de Fozdouro et Burela et Lieyro et Portezelo et Çelero" "70. No obstante, la efectividad real de esta medida resultó limitada, debido a las acciones de Pedro Fernández de Bolaño y su esposa Beatriz de Castro, que no se plegaban completamente a los términos de las sentencias ${ }^{71}$.

\footnotetext{
Aponte, Recuento, p. 142, núm. 114.

${ }_{66}$ Como paso previo a la vía judicial, el 14 de marzo de 1482 el cabildo mindoniense retiraba formalmente la "suçesion de Burela de manos del sennor Pedro de Volanno ou de outro qualquer ocupador et leuador que la lieue et queser lebar o ocupar segun que la tenia aforada Ares Vasques de Vaamonde", integrándose entre los bienes del "comunete", que habían arrendado los canónigos Vasco Martínez y Álvaro González da Pena. Cal Pardo, Mondoñedo-catedral, cidade, bispado-, docs. 229 y 241, pp. 323-325 y 339-341.

67 Cal Pardo, Colección diplomática medieval, doc. 201B, pp. 401-403.

68 Ibidem, docs. 202A y 202B, pp. 405-416.

69 Ibidem, doc. 202C, pp. 416-417.

70 Ibidem, docs. 203A y 203B, pp. 418-420.

71 En el contexto de la visita de los Reyes Católicos a la "çibdad de Santiago de Galizia" en la segunda mitad del año 1486, el cabildo de la iglesia de Mondoñedo demandó a Beatriz de Castro ante los monarcas, siendo acusada de usurpar las "heredades de Cristoboo et Portoselo et las terrarias de los dichos logares" que pertenecían a la "Suçesion de Burela". Ibidem, doc. 205C, pp. 425-426. (05/10/1486). Con todo, en el marco de un escenario histórico y biográfico-familiar sumamente complejo y convulso [García Oro y Portela Silva, "Osorios, Bolaños, Pardos y Ribadeneiras", pp. 151-180], se testimonia finalmente el acceso de las autoridades capitulares mindonienses al control efectivo de un sector (cuantitativamente reducido y atomizado) de los bienes y rentas englobados en la "suçeson de Burela", distribuidos "desde la ponte da Espineyra fasta la vyla de Vyueyro". Cal Pardo, Mondoñedo -catedral, cidade, bispado-, docs. 277 (28/07/1486), 288 (15/07/1487), 291 (04/07/1487), 292 (14/08/1487), 293 (07/11/1487), 297 (07/07/1488) y $341(17 / 04 / 1493)$, pp. 388-389, 401, 404-411, 416-
} 
Sin duda, el máximo exponente de este desacato se encuentra en las cláusulas del testamento de Pedro Fernández de Bolaño -"Pedro de Bolaño e de Balboa" en este texto-, otorgado el 20 de agosto de 1491. Entre sus mandas, se estipulaba la entrega a su hijo Bernardo de Bolaño de los "vasallos que yo he e me pertenesçen en el obispado de Mondoñedo por suçesion e herençia de Doña Mayor de Vaamonde mi señora madre, asy propios como fueros, segun e en la manera que me los mando e dexo Martin Vazquez de Vaamonde, mi hermano, que santa gloria aya, de quien las herede e ove", así como la concesión a su hija Mayor de Bolaño de "mi casa e porto de Burela con todos sus heredamientos e rentas" 72 .

Aparentemente, con este acto de última disposición -claramente contrario a las diferentes resoluciones judiciales y órdenes regias- se cerraba el proceso de patrimonialización de una parte cualitativamente sustancial de los bienes integrados en la "Suçesion de Burela" - con la localidad homónima, verdadera joya de la corona, ejerciendo como centro de referencia y base de operaciones-, como culminación de una dinámica basada en el control señorial efectivo alegal y la preeminencia de los hechos consumados. Con todo, aún restaba un epílogo, cuyos protagonistas fueron Leonor de Bolaño y Alfonso Vázquez de Cabarcos.

Entre la progenie de Pedro Fernández de Bolaño se encuentra una hija ilegítima, Leonor de Bolaño, cuya unión matrimonial se concertó con Alfonso Vázquez de Ca$\operatorname{barcos}^{73}$. Entre las disposiciones de la carta de dote -otorgada el 18 de febrero de 1482 en la localidad de Torés ${ }^{74}$-, se establecía como garantía de cumplimiento de los términos materiales acordados - consistentes en un juro de heredad de treinta cargas de pan anuales y una entrega de veinte mil maravedíes- sus bienes situados "desde la puente de la Espiñera y mariñas de Vibero fasta la villa de Vibero".

Pues bien, ante la aparente inobservancia de las disposiciones incluidas en el pacto dotal, se habrían activado las cláusulas indemnizatorias, y Alfonso Vázquez de Cabarcos se habría adueñado del "puerto de Burela con su torre y casa y casas y casares y cavanas de pescadores y viñas, con la presentaçión del benefiçio, censos, pechos y derechos y lutuosas y señorío y juridiçión" ${ }^{\text {"75 }}$. Sin duda, con esta acción se quebrantaban

417 y 469-470. En este último documento, el escudero Juan Abad, "vessino de la Marinna de Biueyro", recibía el arrendamiento de la "Subçesion de Burela que solia leuar donna Mayor de Vaamonde con los çeleeros de Pedroso et Portisuelo et terrarias de Vilachaa et Sumoas".

72 García Oro, "Viveiro y la familia de los Pardo de Cela", doc. 14, pp. 195-198. El contenido del testamento se glosa brevemente en: Presedo Garazo, "Elite hidalga y poder señorial”, p. 131.

73 Este hidalgo mindoniense se testimonia en la órbita social, incluso familiar, del mariscal Pedro Pardo de Cela. Así, por ejemplo, el 25 de octubre de 1464 Álvaro de Cedofeita, abad del monasterio benedictino de Vilanova de Lourenzá, aforó a Pedro Pardo de Cela y a su esposa Isabel de Castro los lugares de Galgao, Quende y Bembibre (Abadín, Lugo) y "o noso çelero de Murinaos" (Barreiros, Lugo). Entre los testigos asistentes a este acto jurídico se refieren Juan Fernández de Cabarcos y su hermano Alfonso Vázquez de Cabarcos. AHN, Códices, 1. 181, ff. $14 \mathrm{v}-15 \mathrm{v}$. Por otra parte, de su cursus honorum consta que el 15 de mayo de 1473 desempeñaba el oficio de "meyrino enna dita çibdade de Vylamayor por meu sennor Pedro Pardo et seu lugartenente". CAL PARDO, Tumbo Pechado, doc. 446, pp. 402-403. Por cierto, el 29 de julio de 1474 el clérigo Pedro Gil accedía a la canonjía que había quedado vacante tras la renuncia forzosa de Juan González Saco "por la grande treyçon que tyna ordenada con Fernando Dias Teyxeyro de tomaren a iglesia de Mondonnedo et mataren ao sennor mariscal et Afonso Vasques de Cabarcos et poeren a sacomano a çibdade". Cal Pardo, Mondoñedo -catedral, cidade, bispado-, doc. 136, pp. 203-204. Además, el 11 de agosto de 1482 firmaba el acuerdo que subscribía un sector significativo de la nobleza gallega en defensa de los patronatos laicos sobre los beneficios eclesiásticos: "Alfonso Vasques de Cabarcos por sy e por Pedro de Cabarcos e Constanza Lopes su hermana". García Oro, Galicia en la Baja Edad Media, doc. XI, pp. 314-320.

74 San Xoán de Torés, As Nogais (Lugo).

75 Archivo de la Real Chancillería de Valladolid (en adelante ARChV), Registro de Ejecutorias (en adelante RE), c. 311, núm. 51, ff. 1r-16v. (Año 1516). 
los términos del testamento de Pedro Fernández de Bolaño, quien había otorgado su "casa e porto de Burela" a su hija Mayor de Bolaño.

A comienzos del siglo XVI, y a consecuencia de ese conflicto de intereses, se iniciaba un largo pleito entre Mayor de Bolaño - junto con su esposo Bernardino de Castellanos-y Alfonso Vázquez de Cabarcos, acusado éste de usurpación. La denunciante apelaba a su condición de hija legítima y heredera de Pedro Fernández de Bolaño y reclamaba la entrega efectiva del señorío y tenencia del puerto de Burela. En las sucesivas instancias judiciales, se reconocieron los derechos de la demandante, compeliéndose a que fuese posesionada en esos bienes radicados en el septentrión lucense pero, una vez más, se impuso la fuerza de los hechos, y ese patrimonio continuó bajo control de los sucesores de Leonor de Bolaño y Alfonso Vázquez de Cabarcos ${ }^{76}$.

Así culminaba el proceso de señorialización laica y patrimonialización nobiliaria de un área territorial y jurisdiccional perteneciente al dominio capitular mindoniense. En el transcurso del siglo XV, la combinación de factores generales -como la inestabilidad política y social regional- y circunstancias concretas -como la presencia de deudos y parientes entre las altas dignidades catedralicias, incluso en el episcopado (Álvaro Núñez de Isorna o Pedro Ares de Vaamonde), o en el ejercicio de la encomienda laica (Pedro Pardo de Cela)- favoreció el acceso de representantes de la nobleza local a determinados bienes eclesiásticos, cuyo control lograron mantener y transmitir a sucesivas generaciones hasta su enajenación, asunción e integración, arrostrando con fuerza y hechos los continuos, aunque infructuosos, intentos de recuperación de la iglesia de Mondoñedo.

\section{El paisaje histórico local tardomedieval (siglos XV-XVI): la evolución y configuración territorial de una entidad polinuclear (Burela do Cabo, Vila do Medio, Puerto de Burela y Vilar)}

A continuación de la exposición de los principales episodios relacionados con la institución y evolución histórica de la "Suçesion de Burela", resulta indispensable el abordaje de la configuración territorial local en los últimos compases de las centurias tardomedievales. ¿Se testimonia el impacto del proceso de señorialización y patrimonialización, con sus múltiples derivadas, en el entramado de ocupación y organización del espacio? La respuesta a esta cuestión debe ser claramente afirmativa,

76 De la unión matrimonial de Leonor de Bolaño y Alfonso Vázquez de Cabarcos nacieron al menos tres vástagos:

* Fernán Díaz de Ribadeneira, ** Pedro de Bolaño y *** Ana Vázquez. * Homónimo del bisabuelo materno y del hermanastro paterno de su madre. Avecindamiento: San Xusto de Cabarcos (Barreiros, Lugo). Primera esposa: María Fernández de Saavedra. Hijos: Fernán Ares de Saavedra (casado con Catalina Osorio), Ares Pérez Pardo y Leonor de Bolaño. Carta de vínculo: 22 de agosto de 1559. Archivo Histórico Diocesano de Mondoñedo (en adelante AHDM), Burela, 1740, ff. 115v-116r, 131r y 132r-135r. AHN, Órdenes MilitaresCaballeros_Santiago (en adelante OM-CS), exp. 5329 ("Fernando de Miranda y Ossorio", nieto materno de "Fernando Arias de Savedra y Rivadeneyra" y "Catalina Ossorio”. Años 1630/1631), ff. 23r-32v. ** Homónimo de su abuelo materno. Esposa: Mayor Martínez. Hijo: Ares Vázquez de Bolaño, casado con Bárbara Osorio. Sobrino: Pedro Gutiérrez de Cabarcos, que residió en su "casa del puerto de Burela". Testamento: 18 de junio de 1560 [Ordena la entrega de un real de plata al "Hospital de Santiago de España"]. Codicilo: 8 de enero de 1561 [Recuerda la manda de "Alonso Vázquez de Cabarcos mi padre" destinada a "Pedro Pardo de Cavarcos su sobrino"]. Defunción: c. 20 de enero de 1561. Lugar de enterramiento: Iglesia de Santa María de Burela. ARChV, RE, c. 3313, núm. 5, ff. 1r-6v. *** El 31 de enero de 1533 fray Juan de Valderrama, abad del monasterio de San Salvador de Vilanova de Lourenzá, aforó a Fernán Díaz de Ribadeneira y a “Ana Vasques, fija de Afonso Vasques de Cabarcos" las rentas monásticas en Santa María Madalena de Cedofeita, Santiago da Castiñeira y Vilamariz (Ribadeo, Lugo) "segundo lo solía llevar Afonso Vazques de Cabarcos". AHN, Códices, 1. 181, f. 30r. 
registrándose, sobre todo en la etapa cenital, una serie de continuidades, evoluciones y mutaciones en el tejido burelense, en ocasiones estrechamente vinculadas con los actores y factores referidos anteriormente.

El territorio de la antigua villa de Superato de Burela altomedieval se muestra sometido a un doble proceso de fragmentación y recomposición, constatándose el surgimiento del núcleo de "Burela de Cavo", que se desarrolla como entidad poblacional en el sector nororiental de la falda del Monte Castelo. En el transcurso de la segunda mitad del siglo XV, la fisonomía de este entorno resultaba alterada con la introducción de una edificación singular -la "torre de Burela de Cavo"77, o "casa fuerte de Burela" ${ }^{7}$-, un elemento nuevo en que se concentran múltiples semánticas.

Entre otras formas, descrita como una "cassa fuerte con su torre de omenaje"79, se trataría de un claro ejemplo de fortaleza señorial ${ }^{80}$, en la cual se combinan los elementos militares y residenciales ${ }^{81}$, actuando a la vez como morada de miembros del linaje titular -o de sus oficiales-, representación de su nobleza ${ }^{82}$ y símbolo de su dominio $^{83}$.

Asimismo, esta casa fuerte burelense podría ser considerada como el resultante local de una dinámica tardomedieval consistente en la "bajada al llano" de los recintos fortificados ${ }^{84}$. Mientras el castello Aquilar representaba aquellos "castellares viejos" que, construidos en "las pennas brauas e los oteros" 85 , se mostraban obsoletos en el nuevo contexto político, socioeconómico y jurisdiccional, este nuevo tipo de fortificaciones señoriales lograba imbricarse en la multiforme configuración de las entidades de población, manteniéndose en contacto directo con su territorio dependiente, sus habitantes y recursos ${ }^{86}$. En ese sentido, la presencia de la torre de Burela do Cabo sería susceptible de relacionarse con el control y la defensa del Puerto de Burela y su actividad económica ${ }^{87}$.

\footnotetext{
AHDM, Burela, 1740, ff. 136v-137r.

AHN, OM-CS, exp. 5329, ff. 30r y 32r.

79 Ibidem, f. $1 \mathrm{r}$.
}

${ }^{80}$ Con respecto a esta tipología, suscribimos las consideraciones expresadas en: Pérez de Tudela y Velasco, "El castillo señorial", pp. 163-176; si bien aplicadas a una esfera territorial y señorial de menores dimensiones.

81 Precisamente en relación con ese aspecto habitacional, cabría señalar que asimismo aparece referida como "casa y palaçio de Burela". AHN, OM-CS, exp. 5329, f. 31r.

82 Desde una perspectiva representacional, esta fortaleza señorial se transformó en muestra pétrea de la "limpia, ilustre y antigua nobleza" de su linaje titular, no en vano, un declarante vecino de Santa María de Burela señalaba que "tienen en esta feligresía su casa fuerte y estas diçe el testigo no las be salvo a grandes cavalleros como son los condes de Rivadeo, don Alonso Ordóñez y otros de cuyos nombres no tiene memoria". Ibidem, ff. $1 \mathrm{r}$ y $25 \mathrm{r}$.

83 En 1582, Fernán Ares "O Novo" recibía la herencia paterna y, en el transcurso del acto jurídico y simbólico de toma de posesión, se le "metió dentro de la cassa e lugar de Burela de Cabo contenido y declarado en la dicha scriptura de vínculo del qual a boz de la torre e solar, guerta, cortiñas, heredades e vozes de montes e derecho de apresentar, luctuosas, demás derechos e acziones y heredades e prados, e metad del Puerto de Burela, casas e territorio, aviendo con él cerrado las puertas de la dicha cassa e lugar e aviéndole echado en el regazo tierra, piedra, madera, lossa e teja (...)". AHDM, Burela, 1740, ff. 139r-140r. Así culminaba un proceso sostenido entre madre e hijo, en el cual se ventilaba la cantidad y calidad de los bienes que supuestamente constituyeron la dote de Catalina Osorio. Varios testigos de las probanzas coinciden en afirmar que la parte sustancial del patrimonio vinculado de Fernán Ares de Saavedra se conformaba con "la mitad del Puerto de Burela con sus cassas e la cassa e torre de Burela de Cavo con sus corrales y heredades, árboles [...] arboledo según está zercada" (Alonso Yáñez, herrero) o "la metad del Puerto de Burela juntamente con la torre e lugar y eredades que dizen e nonbran Burela de Cabo" (Rodrigo de Marrube). Ibidem, ff. 137v-138v.

84 Avello Álvarez, Las torres señoriales, pp. 48-52.

85 Ordenamientos de las Cortes de Valladolid de 1325. Cortes de los antiguos reinos, I, p. 381.

86 Avello Álvarez, Las torres señoriales, p. 61.

87 De Fernán Díaz de Ribadeneira, señor de la casa fuerte de Burela en la primera mitad del siglo XVI, se afirma 
Figura 6. Escudo de la torre de Burela do Cabo, con sus anzuelos como característica ${ }^{88}$.

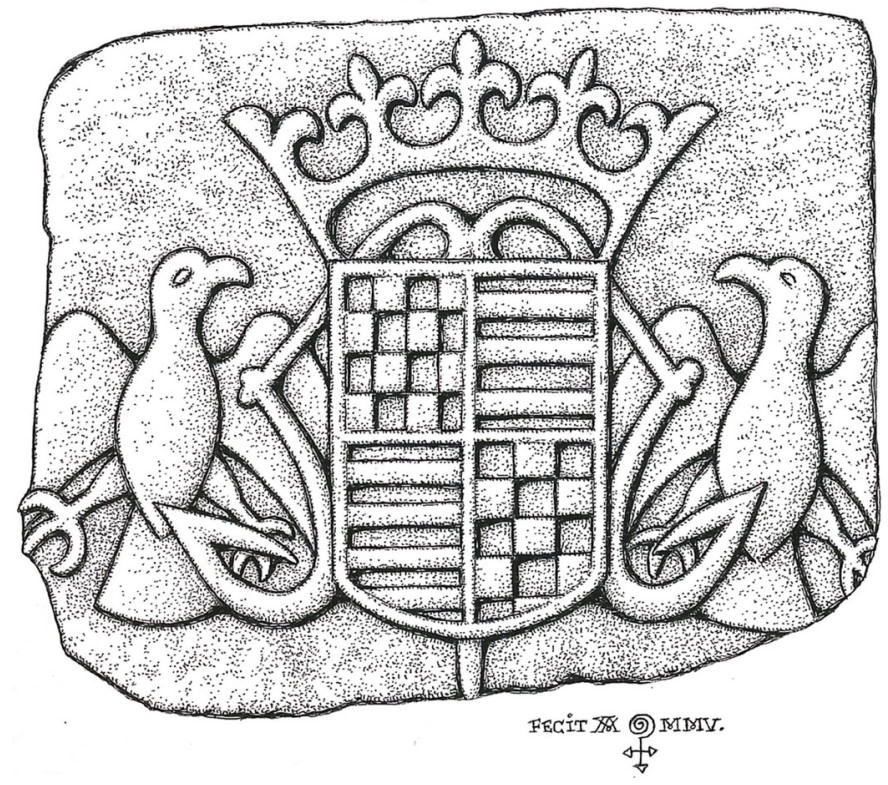

Sin duda, en términos globales, la evolución registrada en el caso de la "yglesia de Burela", templo y feligresía ahora incardinados en el "arçidianadgo de Vyueiro"89, aún resulta más espectacular. En el transcurso de las últimas centurias medievales, se constata la conformación de un núcleo de población en su entorno que, seguramente debido a su localización entre los enclaves de Burela do Cabo y Vilar, recibió la denominación de Vila do Medio ${ }^{90}$.

Al presente, prácticamente no se conservan trazas de su antigua morfología, ni en el barrio ni en la vieja iglesia, ambos elementos desdibujados a causa de la desordenada transformación urbana acaecida en la segunda mitad del siglo $\mathrm{XX}^{91}$. Entre los testimonios supervivientes, se encuentran las pinturas murales conservadas en el interior del templo. Atribuidas a la órbita artística del "Maestro de Mondoñedo" y temáticamente centradas en la pasión, muerte y resurrección de Jesucristo, han sido fechadas a mediados del siglo XVI ${ }^{92}$, precisamente cuando Pedro de Bolaño -titular del señorío y patronato del beneficio curado-resolvió ser sepultado en la "yglesia de Santa María de Vurela"93, iniciándose así una larga tradición familiar.

que "es común opinión mantubo gran lustre y familia armada que le servía en defensa del Puerto de Burela". AHN, OM-CS, exp. 5329, f. 30rv.

88 Dibujo de Xosé Antón García González-Ledo, 2005. C Instituto de Estudios Gallegos Padre Sarmiento (Consejo Superior de Investigaciones Científicas).

89 Cal Pardo, Colección diplomática medieval, doc. 206, pp. 431-432.

90 Este asentamiento se encuentra catalogado, atribuyéndosele una adscripción cronológica medieval y una tipología cultural poblacional. Xunta de Galicia, GA27902005. Concello de Burela, 105.

91 Río Otero, "Burela: de aldea a cidade", pp. 319-342.

92 Pardo Fernández, "La Pasión de Cristo", pp. 215-218.

93 "Ytem mando mi cuerpo a la tierra donde fue formado, e quiero y es mi boluntad sea sepultado en la yglesia de Santa María de Vurela, donde soy feligrés, delante el altar de Nuestra Señora, en el qual dicho lugar y entierro mando e querría que se me hiciese mi entierro e sepultura como pertenecze a mi estado, e por la dote de ella mando a la fábrica de la dicha yglesia la mitad de un tarreo y heredad que tengo de por medio con la dicha 
Figura 7. Iglesia de Santa María de Burela.

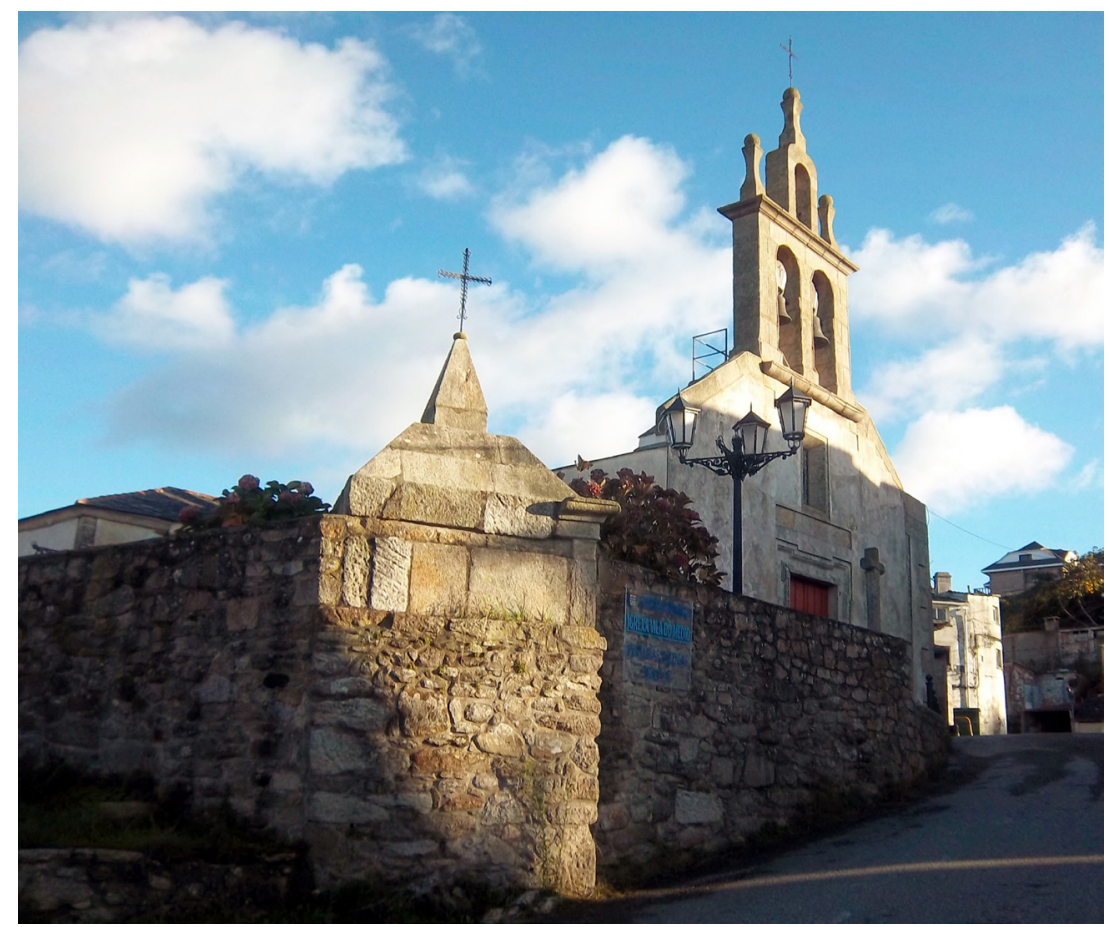

Documentado desde finales del siglo XV, concretamente desde su referencia en las últimas voluntades de Pedro Fernández de Bolaño, la existencia del "porto de Burela" se incardina en un marco histórico determinado: el surgimiento de una serie de áreas portuarias señoriales en el litoral cantábrico mindoniense, más concretamente, en la marina comprendida inicialmente "desde la agua que dizen d'Amasma fasta el Estero de Llouia"94, pero extendida ulteriormente "desde el rio de la Masma fasta Aguillos de Ortigueira"95.

Se trata de una franja costera amplia, situada bajo el dominio fáctico de las autoridades de la villa de Viveiro, que consideraban ese sector territorial una zona de extensión económica exclusiva. Precisamente, el factor favorecedor de la aparición de este tipo de establecimientos portuarios fue el acceso señorial al control de los resortes de poder local.

En ese sentido, las coordenadas históricas confluyen en la figura de Pedro Pardo de Cela quien, el 23 de mayo de 1464, se intitulaba "alcalde ena villa de Vivero por el Rey noso señor justicia et comendeyro do obispado de Mondoñedo”, refrendándose textualmente su condición de alcalde regio del "concello e sua terra e jurdiçon" el 27 de julio de $1465^{96}$. Aunque con altibajos más o menos pronunciados ${ }^{97}$, logró capear

yglesia”. ARChV, RE, c. 3313, núm. 5, ff. 4v-5r

94 Hernández, Las rentas del rey, I, p. 260. (24/02/1290).

95 García Oro y Romaní [Martínez], "Viveiro en el siglo XVI", doc. 40, pp. 138-139. (02/03/1532).

96 Esta cita se encuentra en: Villaamil y Castro, "El mariscal Pardo de Cela", p. 93.

97 Sobre esta cuestión, entre las síntesis recientes podría señalarse: Rubio Martínez, "Los primeros vizcondes de Altamira", pp. 95-114, especialmente 101-106. 
sucesivos temporales y mantener su influencia en esta área de la geografía económica mindoniense hasta el año $1478^{98}$.

Pues bien, durante ese período de tres lustros, el mariscal Pardo de Cela se sirvió instrumentalmente de la coyuntura general y de su dominio del escenario local y llevó a cabo la instauración de los puertos de Masma $^{99}$ (Lugo) y Bares ${ }^{100}$ (A Coruña), ambos abiertos contra legem a la actividad mercantil, y seguramente también Morás ${ }^{101}$ (Lugo).

Asimismo, si se atiende a la concurrencia de determinados elementos -como la coincidencia cronológica (en el último cuarto del siglo XV), la localización (dentro del área de acción de la villa de Viveiro), o las relaciones de parentesco existentes entre los linajes de Pedro Pardo de Cela y Pedro Fernández de Bolaño (suegro y yerno, respectivamente)-, no resultaría aventurado hipotetizar que el "porto de Burela"

98 El momento álgido del ocaso de la hegemonía del mariscal en la villa de Viveiro se alcanzaba el 26 de junio de 1478, cuando el rey Fernando indicaba a "vos el Mariscal Pero Pardo de Cela, mi vasallo, e a todos vuestros escuderos, e omes e criados e apaniaguados" que "entendiendo ser asy complidero a mi señorio e a la execuçion de mi justiçia e al pro e bien comun e pas e sosiego de la villa de Vivero, mi merçed e voluntad es que por el presente vosotros ni alguno de vos non entredes ni estedes en ella, nin en su tierra e termino e jurediçión, fasta tanto que para ello ayades mi carta e liçençia e espeçial mandado". García Oro, "Viveiro y la familia de los Pardo de Cela", doc. 2, pp. 181-182.

99 El 26 de junio de 1478 el rey Fernando anunciaba a Pedro Pardo de Cela que había sido informado de que, sin su preceptiva autorización, "avedes fecho y abierto puertos nuevos y fecho cargo y descargo de navíos y barcas y fustas en La Masma y en Vares”, contraviniéndose de esta forma los privilegios, franquicias y libertades de la villa de Viveiro. De resultas, se conmina al mariscal a que "non fagades nin consintades façer el dicho cargo y descargo en los dichos puertos de Masma y Vares que asy disen nuevamente avedes abierto". AGS, Registro General del Sello, 1. 147806, f. 73rv. Casi treinta años más tarde, concretamente el 7 de diciembre de 1506, el conde Pedro de Villandrando y las autoridades municipales de la villa de Ribadeo recibían una carta real, en la cual se informaba de la denuncia de Rodrigo [de] Carranza "arrendador e recaudador mayor de las rentas de las alcavalas e diesmos e alfolies de la villa de Vivero". Se indicaba que entre la "villa de Ribadeo e Vivero ay un rio que se llama La Masma", en donde se realizaba carga y descarga, incurriéndose en quebrantamiento de la legislación fiscal y perjuicio del puerto de Viveiro, de titularidad regia. Ante esta situación, la reina prohibió el desarrollo de esa actividad en la "ria de La Masma". García Oro, "Viveiro y la familia de los Pardo de Cela", doc. 23, pp. 214-215. Por cierto, aún resulta escasamente conocido el grado de implicación del mariscal Pardo de Cela en el tejido productivo de la economía mindoniense medieval. Sin embargo, por ejemplo, quince kilómetros al este del puerto de Masma - concretamente en el término de la feligresía de San Miguel de Reinante (Barreiros, Lugo), en donde aún se conserva el topónimo A Ferrería-, contaba con unas herrerías hidráulicas, entregadas a Alfonso Vázquez de Cabarcos en 1482. Así, se afirma que este "senor de basallos" recibió del "mariscal Pedro Pardo las ferrerías de San Miguel de Reynante, convenía a saber los tres quartos dellas mobientes y corrientes con los beneros y venas de hierro y aparejos pertenesçientes a las dichas ferrerías con todo el señorío". ARChV, RE, c. 311, núm. 51, f. 15r.

100 Las noticias relativas a la existencia de un área portuaria, así como de una explotación económica del medio marino litoral, se remontan al 18 de julio de 916, cuando el rey Ordoño II entregaba al obispo dumiensemindoniense Sabarico uillam nomine Uaris cum familia sibi pertinenti per terminum de aqua de ectario et inde per montem dominicum ast per pennam Iuliani et per Montarion usque ad illum portum de Delfino atque Sauris siue ostrarias uel diuesas seu piscarias per aquam de Uilare Berilli. Cal Pardo, Colección diplomática medieval, doc. 2, pp. 12-13. Tres siglos más tarde, se testimonia el desarrollo local de una actividad productiva específica: la pesca de la ballena. Así, en 1291 se refieren los "baleeyros de Vares". Ibidem, doc. 56, pp. 74-80. Sobre esta cuestión, resulta de interés la consulta de: Valdés Hansen, “Origen y consolidación”, pp. 441-475, especialmente 452-469.

101 El 19 de mayo de 1484 los Reyes Católicos comunicaban a sus principales agentes en el reino de Galicia -Diego López de Haro, su justicia mayor, y Sancho García del Espinar, su alcalde mayor- "que por parte de Doña Isabel de Castro, muger del Mariscal Pero Pardo de Cela, nos fue fecha relaçion que despues de la fin e muerte del mariscal su marido, Don Fernando de Acuña, nuestro justiçia mayor del dicho Reyno, tomo e secresto e confisco todos los bienes muebles e rayses al dicho mariscal pertenesçientes, a buelta de los quales dis que le tomo e confisco el su puerto de Morales con l'asiento e palaçio de la Reguera de Ferrol que le avia obligados e ypotecados por quantia de tres mill florines que valian las arras e dote quella troxiera a su poder que Galaor Mosquera su primero marido le diera al tiempo que con el casara". Sin embargo, entre los oficiales reales se sospechaba firmemente que esa alegación era falsa, y que los bienes reclamados como dotales habían pertenecido a la hacienda personal del mariscal Pardo de Cela. García Oro, "Viveiro y la familia de los Pardo de Cela", doc. 10, pp. 190-191. 
se hubiese establecido definitivamente en ese abanico temporal (años 1464-1478), al socaire de las otras fundaciones mariscalianas ${ }^{102}$.

Otro argumento a favor del carácter reciente de sus orígenes sería su configuración a comienzos del siglo XVI, cuando el "puerto de Burela" se muestra como un núcleo dotado de una estructura sencilla, con sus casas, casares y cabañas de pescadores $^{103}$, cuya base económica se concentraría seguramente en la pesquería costera endógena ${ }^{104}$-en la cual alcanzaría una especial relevancia la sardina-, que coexistiría (de forma más o menos pacífica) con la caza de ballenas, de naturaleza exógena, que efectuaban "muchos estrangeros del Reyno de Françia e de otros reynos e de la provinçia de Guipuzcoa e del condado de Vizcaya" 105 .

Sin duda, la significativa productividad de la actividad ballenera ${ }^{106}$ atrajo la atención y el interés de los titulares del puerto de Burela -"con sus casas, terretorio y heredades"- que, a mediados del siglo XVI, eran los hermanos Fernán Díaz de Ribadeneira y Pedro de Bolaño, quienes incluyeron en su configuración una nueva infraestructura especializada, relacionada con la captura de los cetáceos: la atalaya ${ }^{107}$. Así se completaba la fisonomía material de un núcleo dotado de un marcado carácter marinero inicial, que se fue transformando, mestizándose con usos agrarios y artesanales según avanzaban los siglos de la Edad Moderna ${ }^{108}$.

102 La primera referencia gráfica conocida del "porto de Burela" se encuentra en el portulano del cartógrafo italiano Grazioso Benincasa, datado en 1466, en el cual aparece como "Virella". Atlas nautique de l'océan Atlantique Nord-Est, de la mer Méditerranée et de la mer Noire. BNF, département des Cartes et plans, CPL GE DD-2779 (RES).

103 ARChV, RE, c. 311, núm. 51, ff. 1v-2r, 9r y 10r.

104 En el recuento de 1571, al describirse la partida del "Calendario de San Cebrian", se indica que "tienen dos puertos de mar donde hay pescadores que matan pescado y no hay navio para navegar. El uno dellos se dice San Cebrian, que tendrá hasta cuarenta vecinos, el otro Burela que tendrá hasta diez. Estos vecinos tienen por oficio de pescar”. González Muñoz, Galicia en 1571, p. 203.

105 García Oro y Romaní [Martínez], "Viveiro en el siglo XVI”, doc. 40, pp. 138-139. (02/03/1532). El vínculo del área portuaria burelense con la captura de ballenas se testimonia desde el año 1527, cuando Pedro Grande -representante de la villa y concejo de Viveiro, así como procurador de Juan de Chaves, capitán de la nao "San Nicolás"- alegaba que el "puerto de San Cibrao, y Burela, y Masma y Bares eran terminos de la villa de Vivero, por privilegios antepasados de su Cesarea Magestad, y siempre, desde tiempo inmemorial a esta parte, los valeneros y chalupas y otras qualesquier personas que venian a pescar a los dichos puertos y faser carga y descarga y anclage". Ibidem, doc. 114, pp. 247-249.

106 Según el testimonio de Juan Abad, regidor de Mondoñedo y arrendatario de los préstamos de Burela y Lieiro, en el transcurso del año 1546 se habrían matado unas 30 ballenas en los puertos de Burela y San Cibrao -frente a los 8/9 cetáceos pescados en el puerto de Bares-, cuyo valor ascendería a 3.000 ducados. Cal Pardo, Mondoñedo -catedral, ciudad, obispado-, doc. 3517, pp. 758-759.

107 ARChV, RE, c. 3313, núm. 5, ff. 4v-6v y 18v. El 10 de agosto de 1762 Juan Antonio Vázquez Osorio y Bolaño prestaba testimonio, ofreciendo interesante información acerca de las múltiples utilidades de esta construcción. Afirma que "havía una que comúnmente se llamaba y llama atalaya a imitación de una guarita y puesta en un sitio repechoso y alto, desde la qual se rexistra hacia a la mar y también se reconoce a y reconoze el mismo puerto, y el sitio donde se halla tiene el nombre de Atalaya, sin que en el motibado puerto haya otra significación de tal más que tan solamente una casupa que aora se alla desmoronada, y según noticias que tubo el que declara, servía en otro tiempo en el rial (sic) de dispensas, y para el fin de recojerse los vizcaínos cuando cojían alguna ballena y juntamente la carne y grasa de esta, y la espresada atalaya también en otro tiempo servía para en los vizcaínos reconocer las vallenas que pasaban por la mar para cojerlas, y tamvién servía para desde ella rexistrar los bientos, y al presente lo mismo sirbe la motibada atalaya para la coortificación (sic, fortificación) de dicho puerto". Ibidem, f. $65 \mathrm{r}$.

108 El 10 de agosto de 1762 Juan Antonio Vázquez Osorio y Bolaño, vecino de Santa María de Burela, señalaba cómo en las casas del área portuaria "viben personas de distintos oficios y entre ellos también labradores, y en otro tiempo lo executaron marineros, y el producto de dichas casas, huertas y heredades que a ellos se hallan sujetas en el referido tiempo, era mui mayor que a el presente por distintos comercios que havía en el motibado puerto de Burela, como era en armar a las ballenas". Ibidem, ff. 64v-65r. Sobre la evolución, las implicaciones y los impactos de esta actividad económica en este sector territorial cantábrico-mindoniense, resulta recomendable la consulta de: Canoura Quintana, A pesca da balea en Galicia, y Valdés Hansen, Los balleneros en Galicia. 
Finalmente, entre las centurias medievales y modernas, el tejido organizativo territorial local se completaba con el resultado evolutivo del antiguo "villar de Burela". Transformado en el "lugar de Vilar", a mediados del siglo XVI seguía mostrándose como un enclave suburbial, que gravitaba alrededor del "Pazo de Vilar"109.

La revisión de los apeos patrimoniales referidos a las "casas de el Pazo de Vilar, sittas en la feligresía de Burela con sus cortinas, huerttas, tarreos de sus casas con sus testtadas, entradas y salidas" ${ }^{\prime 110}$ revela su carácter complejo, en el cual coexistían su naturaleza de residencia señorial -como morada de Pedro de Bolaño y un buen número de su descendencia inmediata- y su función económica, constituyéndose en el centro de una gran explotación agropecuaria, que contaba con múltiples heredades dedicadas a la cerealicultura ${ }^{111}$, una porción del "molino da Longoyra" -sin duda destinado a la transformación primaria del referido cereal ${ }^{112}$ - y el castañar de Pumeda -fuente de frutos, leña y madera- ${ }^{113}$.

Figura 8. Pazo de Vilar ${ }^{114}$.

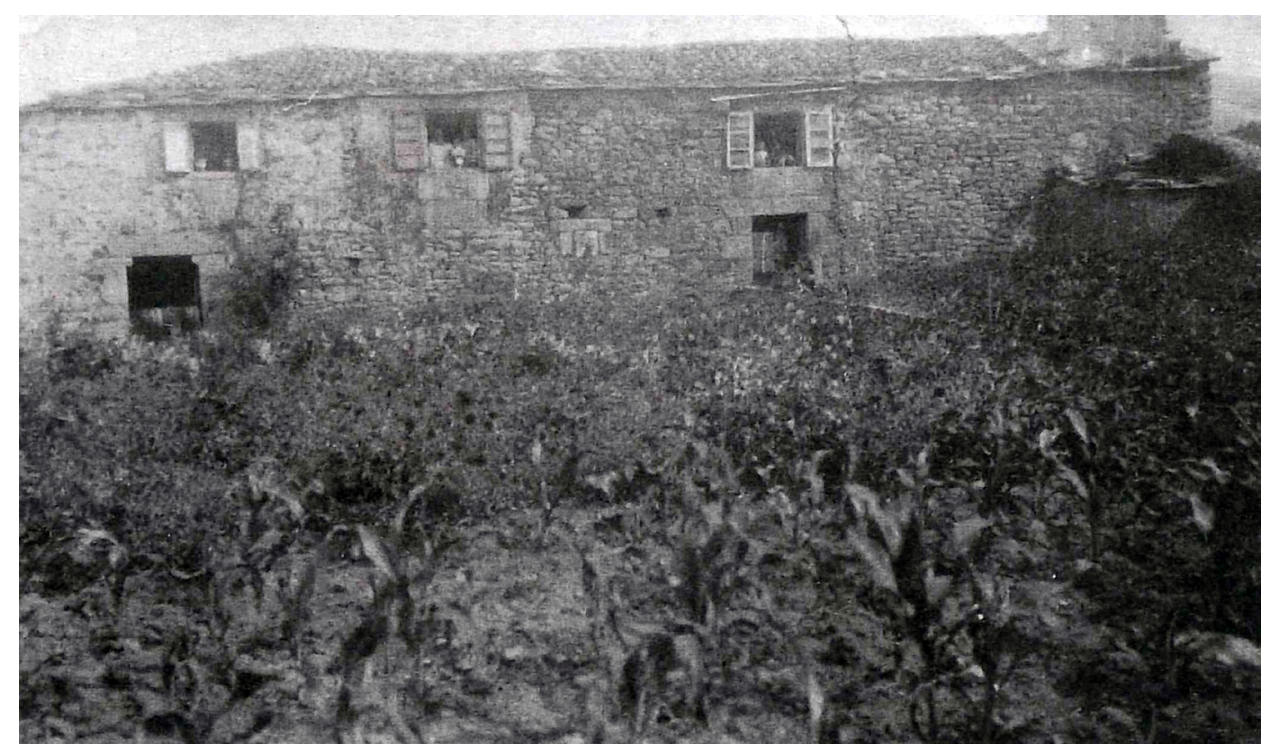

109 De su configuración material, se conoce la existencia de una casa principal rodeada de un muro alto. En el interior del espacio cercado, se hallaban la casucha del ganado, la parra, la huerta de los laureles, la huerta de los limones, etc. Este complejo residencial y productivo limitaba con una parte del sistema viario local, mencionándose el “camino que bá al puerto". ARChV, RE, c. 3313, núm. 5, f. 20r.

110 Ibidem, f. $19 \mathrm{v}$.

111 Se localizaban en A Abesada, A Atalaya, A Barreira, A Cancela de Vilar, A Costa de Pumariño, A Cova, A Ferrería, A Fontela, A Lagoa, A Pena da Aguia, A Veiga da Vila, A Veiga do Castro, Areamarosa, As Cortiñas, As Figueiras, Atallo, Espiñeiro, Milleral, O Camineiro, O Carreiro de Vilar, O Cómaro da Abesada, O Foxo, O Liño, O Outeiro, O Valado, Os Corgos, Portelo y Pumeda.

112 Sobre los cereales cultivados, quizás sea indicio el hecho de que "donna Mayor de Vaamonde que soya lebar esta Suçeson" recibió de Juan Alfonso, clérigo de la iglesia de Burela, "quatro moyos de pan que son quatro carregas de pan huna de trigo et outra de çenteo et outra d-orjo et outra de millo" (es decir, trigo, centeno, cebada y mijo). Cal Pardo, Mondoñedo-catedral, cidade, bispado-, doc. 293, p. 410.

113 ARChV, RE, c. 3313, núm. 5, ff. 6r, 7v-8r, 9r, 19r-20r y 24v-26r.

114 Esta antigua fotografía se encuentra en: Pena Domínguez, Burela: apuntes históricos, p. 74. Agradecemos sinceramente la autorización de reproducción de la imagen al Sr. D. Jesús Rodríguez Pena, y sus gestiones a la Dra. Herminia Pernas Oroza y al Sr. D. José Díaz García. 
A finales del siglo XVI, colofón cronológico de esta secuencia histórica, la villa de Burela se muestra como un asentamiento unitario de estructura polinuclear, en el cual se constatan cuatro focos imbricados socioeconómica y funcionalmente, actuando la red viaria como nexo interno. En primer lugar, Burela do Cabo, sede del poder señorial local, que se simboliza en su torre; en segundo lugar, la Vila do Medio, donde se encuentra la iglesia de Santa María, centro territorial de la feligresía y espiritual de la vida religiosa de sus habitantes; el Puerto de Burela, que irá capitalizando progresivamente la actividad productiva de este enclave del litoral cantábrico gallego y, finalmente, el Vilar, un microcosmos en el que se concretan, a escala reducida, los mismos elementos y mecanismos presentes en la célula madre, respecto de la cual nunca llegó a seccionarse el cordón umbilical ${ }^{115}$.

Figura 9. La configuración polinuclear de Burela aún resultaba constatable a mediados del siglo $\mathrm{XX}^{116}$.

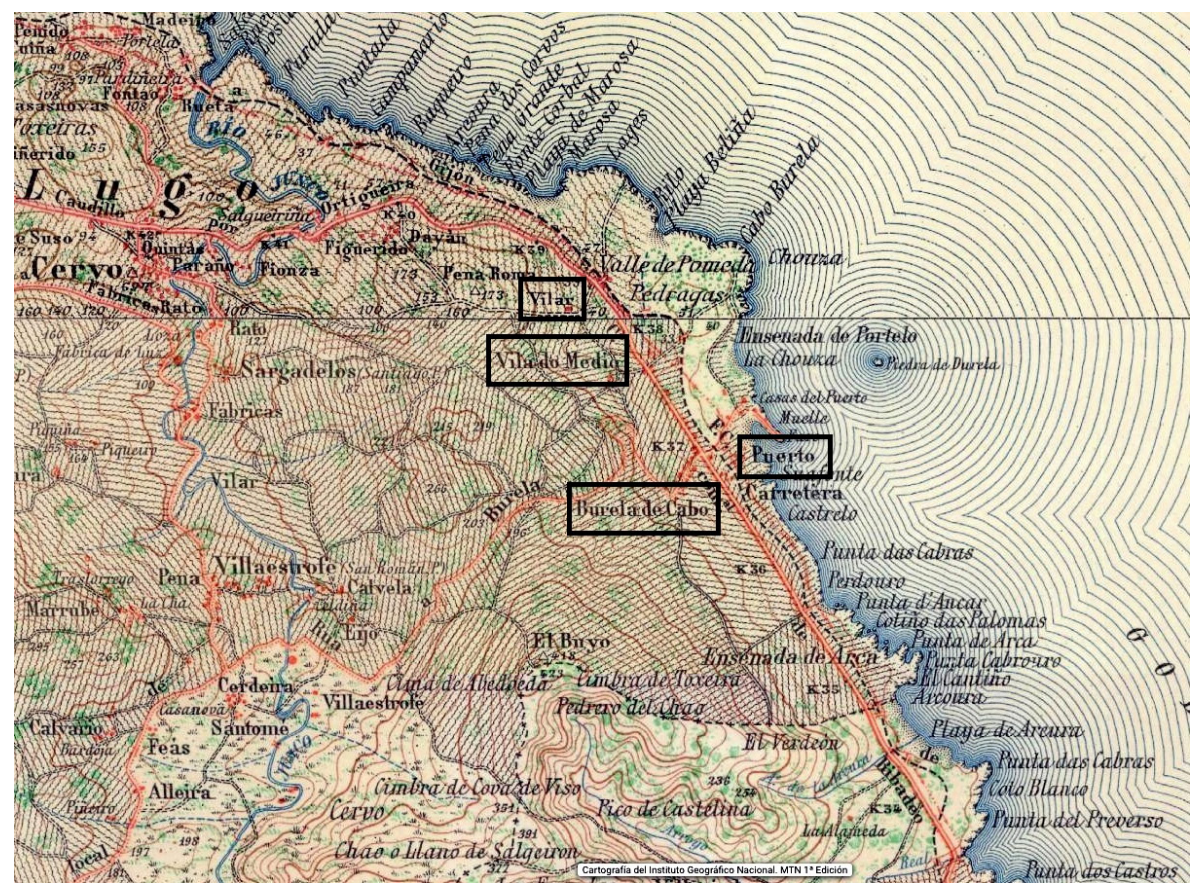

A lo largo de estas páginas, hemos asistido a la evolución histórica, conceptuada como las continuas transformaciones experimentadas en los elementos constitutivos del paisaje antrópico, de un sector concreto del litoral cantábrico gallego, de aquella pars maritima Gallecie alfonsina de las crónicas asturianas ${ }^{117}$. La sinergia de testimonios procedentes de diferentes fuentes de información y disciplinas científicas ha

115 Esa configuración territorial polinuclear, mas funcionalmente unitaria, se consolida y mantiene durante centurias, como se puede comprobar, por ejemplo, en la entrada correspondiente a la feligresía de "Santa María de Burela" del Diccionario de Madoz, en la cual se señala que "comprende los burgos ó 1. de Burela de Cabo, Puerto, Vila do medio y Vilar". Madoz [Ibáñez], Diccionario, IV, p. 502.

116 Mapa Topográfico Nacional 1:50.000 (MTN50). $1^{a}$ ed. Cartografía (C Instituto Geográfico Nacional de España.

117 Adefonsi Tertii Chronica, Ad Sebastianum, núm. 14, Crónicas Asturianas, p. 133. 
revelado un proceso secular que comienza a la orilla del mar, en un hábitat denso, complejo y condicionado naturalmente, cuya específica configuración antropogénica empieza a conocerse lentamente, fruto de los tímidos avances de la investigación arqueológica.

Debido a la confluencia de una serie de sucesos naturales e históricos, entre la Antigüedad tardía y la Alta Edad Media, la ocupación humana basculó desde la línea de la costa al límite interior de la "rasa cantábrica", asentándose en las estribaciones de los Montes do Buio. Las primeras referencias documentales ofrecen una panorámica en la cual la villa de Superato de Burela y el castello Aquilar, con sus respectivas semánticas, resultan coprotagonistas de la organización del territorio -entendido en sus sentidos espacial y social-, instituyéndose en punto de partida, en embrión de un hábitat que, de manera gradual, cambia y adquiere mayor complejidad fruto de la interacción de factores endógenos y exógenos.

Desde las centurias plenomedievales, los testimonios escritos muestran la aparición del "villar de Burela" en el contorno de la villa homónima y, en el interior de esta unidad de habitación y producción, la transformación de su núcleo en Burela do Cabo, así como el surgimiento progresivo, dentro de sus antiguos términos, de una serie de microentidades complementarias que gravitan en torno a la iglesia $y$, más tarde, al puerto. Precisamente, en ese sentido, en la última etapa del medievo se registra el regreso de la ocupación socioeconómica permanente a la franja costera, cerrándose así un círculo iniciado siglos atrás, si bien los parámetros resultaban substancialmente diferentes al punto de partida.

Este artículo se constituye en un ejercicio de análisis territorial construido mediante una aproximación bottom-up, es decir, recurriéndose al estudio individualizado y detallado de las células básicas de ocupación y organización del espacio, entendidas como variables de un sistema antropogénico compuesto, complejo y dinámico. Este tipo de trabajos se consideran necesarios y útiles en cuanto soportes funcionales de futuras investigaciones de mayor espectro geográfico que, seguramente, significarán un avance en el conocimiento del paisaje histórico gallego medieval.

Sin duda, se trata de una tarea ardua, cuyo grado de dificultad aumenta de manera exponencial cuando se someten a escrutinio casos localizados en el litoral cantábrico gallego, verdadera cenicienta de este tipo de estudios ${ }^{118}$. Ciertamente, salvo honrosas y cualificadas excepciones, temáticamente centradas en el tejido urbano primario - con la villa de Viveiro y el burgo de Ribadeo a la cabeza, y aún así, flaqueando cuando se afrontan sus antecedentes y orígenes territoriales en época temprano y altomedieval-, escasean substancialmente los análisis diacrónicos y sincrónicos de aglomerados medievales secundarios - como Foz o San Cibrao (Cervo), además de Burela- y terciarios - como Meirengos (Ribadeo), Marzán (Foz) o Area de Estabañón (Viveiro)-. Con este artículo consideramos que se quiebra esa tónica de ausencias, abriéndose camino a una reconsideración histórica más profunda y actualizada -en métodos y objetivos- del poblamiento medieval de la Mariña cantábrica gallega, hasta ahora uno de los "puntos ciegos" del análisis regional de la Galicia de la Edad Media.

118 Sirva como muestra de ese fenómeno su ausencia en síntesis recientes como: Ballesteros-Arias y Blanco-Rotea, "Aldeas y espacios agrarios altomedievales", pp. 115-135. Sánchez Pardo, "Poblamiento rural tardorromano y altomedieval”, pp. 285-306. Pallares [Méndez] y Portela [Silva], "Para una lectura histórica del paisaje”, pp. 97-151. 


\section{Bibliografía}

Andrade Cernadas, José Miguel, "O "conde santo" Osorio Gutiérrez e as orixes do mosteiro de Lourenzá", en Enrique Fernández Castiñeiras y Juan Manuel Monterroso Montero (dirs.), Opus Monasticorum II. Arte benedictina nos Camiños de Santiago, Santiago de Compostela: Xunta de Galicia, 2006, pp. 315-324.

Aponte, Vasco de, Recuento de las casas antiguas del Reino de Galicia, ed. Manuel Cecilio Díaz y Díaz... [et al], Santiago de Compostela: Xunta de Galicia, 1986.

Arias Vilas, Felipe, “A Mariña lucense na época galaico-romana: un poboamento e uns recursos diversificados", Lucensia, XIII/27 (2003), pp. 261-276.

Atlas nautique de l'océan Atlantique Nord-Est, de la mer Méditerranée et de la mer Noire, Bibliothèque nationale de France (BNF), département des Cartes et plans, CPL GE DD-2779 (RES).

Avello Álvarez, José Luis, Las torres señoriales de la Baja Edad Media asturiana, León: Universidad de León, D.L. 1991.

Baliñas Pérez, Carlos, Do mito á realidade. A definición social e territorial de Galicia na Alta Idade Media (séculos VIII e IX), Santiago de Compostela: Fundación Universitaria de Cultura, 1992.

- Gallegos del año mil, A Coruña: Fundación Pedro Barrié de la Maza, 1998.

Ballesteros-Arias, Paula y Blanco-Rotea, Rebeca, "Aldeas y espacios agrarios altomedievales en Galicia", en Juan Antonio Quirós Castillo (ed.), The archaeology of early medieval villages in Europe, Bilbao: Universidad del País Vasco, D.L. 2009, pp. 115-135.

Balseiro García, Aurelia, El oro prerromano en la provincia de Lugo, Lugo: Diputación Provincial de Lugo, 1994.

Burela (Lugo), Suplemento del Boletín Informativo Lucus, 43 (1996).

Cal Pardo, Enrique, Mondoñedo -catedral, ciudad, obispado- en el siglo XVI. Catálogo-regesta de la documentación del siglo XVI del Archivo de la Catedral de Mondoñedo, [Santiago de Compostela]: Xunta de Galicia, 1992.

- (ed.), Colección diplomática medieval do arquivo da catedral de Mondoñedo, Santiago de Compostela: Consello da Cultura Galega, 1999.

- Episcopologio Mindoniense, Anexo XXVIII de Cuadernos de Estudios Gallegos, Santiago de Compostela: Instituto de Estudios Gallegos Padre Sarmiento, 2003.

- (ed.), Tumbos del archivo de la catedral de Mondoñedo. Calendarios, Lugo: Diputación Provincial de Lugo, 2005.

- (ed.), Tumbos de la catedral de Mondoñedo. Tumbo Pechado, Lugo: Diputación Provincial de Lugo, 2006.

- (ed.), Mondoñedo -catedral, cidade, bispado- na segunda metade do século XV, Lugo: Deputación de Lugo, 2015.

Canoura Quintana, Andrés, A pesca da balea en Galicia nos séculos XVI e XVII, [Santiago de Compostela]: Xunta de Galicia, D.L. 2002.

Carro Otero, José y Varela Ogando, María Luisa, "Estudio anatonomo-antropológico del esqueleto atribuido a D. Osorio Gutiérrez, el 'conde santo' de Villanueva de Lorenzana (Lugo)”, Cuadernos de Estudios Gallegos, XXXV/100 (1984-1985), pp. 79-114.

Christys, Ann, Vikings in the South. Voyages to Iberia and the Mediterranean, Londres: Bloomsbury, 2015.

Concello de Burela, Plan Xeral de Ordenación Municipal, 2014, catálogo patrimo- 
nial, fichas número 101, 102, 103, 104, 105 y 106. [En línea]. www.burela.org/ PXOM/index.htm. [Consulta: 15/10/2016].

Cordeiro Maañón, Luis, "Análisis de los asentamientos costeros en el sector oriental de la provincia de Lugo", en Raquel Martínez Peñín y Gregoria Cavero Domínguez (eds.), Evolución de los espacios urbanos y sus territorios en el Noroeste de la Península Ibérica, León: Ediciones El Forastero, 2015, pp. 93-122.

Cortes de los antiguos reinos de León y de Castilla, ed. Real Academia de la Historia, Madrid: Imprenta y estereotipia de M. Rivadeneyra, 1861, t. $1^{\circ}$.

Crónicas Asturianas, eds. Juan Gil Fernández, José L[uis] Moralejo [Álvarez] y Juan I[gnacio] Ruiz de la Peña, Oviedo: Universidad de Oviedo, 1985.

CulturaGalega, "As xoias do tesouro dos Gil", 2015. [En línea]. www.culturagalega. org/noticia.php?id=25118. [Consulta: 18/10/2016].

Erkoreka [Barrena], Anton, "A furore normanorum, libera nos Domine. Previkingos y vikingos asolando la costa vasca (siglos V-X)", Itsas Memoria. Revista de Estudios Marítimos del País Vasco, 5 (2006), pp. 15-31.

Fábrega Álvarez, Pastor, Poblamiento y territorio de la cultura castreña en la comarca de Ortegal, Cadernos de Arqueoloxía e Patrimonio 19, Santiago de Compostela: Universidad de Santiago de Compostela, 2004.

Fernández Ochoa, Carmen, "Materiales arqueológicos de "Los Castros" (Ribadeo, Lugo)", en Homenaje al Prof. Martín Almagro Basch, Madrid: Ministerio de Cultura, 1983, 4 vols.

Fernández Ochoa, Carmen y Morillo Cerdán, Ángel, De Brigantium a Oiasso: una aproximación al estudio de los enclaves maritimos cantábricos en época romana, Madrid: Foro, D.L. 1994.

— "La ruta marítima del Cantábrico en época romana", Zephyrus, XLVI (1994), pp. 225-231.

Fernández Pintos, María Pilar, Sondeos valorativos en el Castro de O Campón (Burela, Lugo). Informe preliminar y propuesta de ampliación, 2004. Servizo de Arqueoloxía, Dirección Xeral do Patrimonio Cultural, Xunta de Galicia.

- Segunda fase de excavación en el Castro de "O Campón”, acceso al puerto de Burela. Informe preliminar. Superficie de ampliación, 2004. Servizo de Arqueoloxía, Dirección Xeral do Patrimonio Cultural, Xunta de Galicia.

Ferreiro Alemparte, Jaime, Arribadas de normandos y cruzados a las costas de la Península Ibérica, Madrid: Sociedad Española de Estudios Medievales, 1999.

Flor [Rodríguez], Germán, "Las rasas asturianas: ensayos de correlación y emplazamiento", Trabajos de Geología, 13 (1983), pp. 65-81.

Flórez, Enrique, España Sagrada. Theatro geographico-historico de la Iglesia de España, $2^{\mathrm{a}}$ edic., Madrid: Oficina de Pedro Marín, 1789, t. XVIII.

García Oro, José, "Viveiro y la familia de los Pardo de Cela", Estudios Mindonienses, 4 (1988), pp. 151-232.

- Galicia en la Baja Edad Media. Iglesia, señorío y nobleza, 2a edic., Noia [A Coruña]: Editorial Toxosoutos, 1999.

García Oro, José y Portela Silva, María José, “Osorios, Bolaños, Pardos y Ribadeneiras: las casas nobles lucenses, camino de la Modernidad", Anuario Brigantino, 25 (2002), pp. 151-180.

García Oro, José y Romaní [Martínez], Miguel, "Viveiro en el siglo XVI. Estudio histórico y colección documental", Estudios Mindonienses, 5 (1989), pp. 13-269. 
Gómez Vila, Javier, Vias romanas de la actual provincia de Lugo, Santiago de Compostela: Universidad de Santiago de Compostela, 2005.

González Fernández, Alberto y Ricart Guillot, Susana, Prospección arqueológica del yacimiento de O Campón, Burela. Informe Valorativo. Memoria, 1999. Servizo de Arqueoloxía, Dirección Xeral do Patrimonio Cultural, Xunta de Galicia.

González Muñoz, María del Carmen (transc. y ed.), Galicia en 1571: población y economía, Sada [A Coruña]: Ediciós do Castro, 1982.

González Paz, Carlos Andrés, La arquitectura militar medieval en la comarca lucense de A Mariña Central, Lugo: Universidad de Santiago de Compostela, 2004.

— "Fortificaciones medievales en tierra de Viveiro", Estudios Mindonienses, 21 (2005), pp. 585-629.

- Osorio Gutiérrez, o "conde-santo" de Vilanova de Lourenzá, Lourenzá [Lugo]: Concello de Lourenzá, 2009.

- "Catro exemplos de fortificacións altomedievais galegas do século X: Castellum de Aranga, Castellum Minei, Castellum Berreti e Castellum de Citofacta", en Francisco Singul [Lorenzo] (dir.), Rudesindus. "San Rosendo. O seu tempo e o seu legado", [Santiago de Compostela]: Xunta de Galicia, D.L. 2009, pp. 359368.

- O bispado de Mondoñedo na Idade Media: territorio, comunidade e poder, Santiago de Compostela: Universidad de Santiago de Compostela, 2015.

González Soutelo, Silvia, El valor del agua en el mundo antiguo. Sistemas hidráulicos y aguas mineromedicinales en el contexto de la Galicia romana, A Coruña: Fundación Barrié, 2011.

González Soutelo, Silvia y Fernández Pintos, Pilar, "Los pavimentos romanos de teselas cerámicas: el ejemplo del yacimiento "O Campón" (Burela, Lugo)", en Mosaicos romanos: fragmentos de cultura nas proximidades do Atlántico, Condeixa-a-Nova: Associação Portuguesa para o Estudo e Conservação do Mosaico Antigo, APECMA/AIEMA, 2015, pp. 322-329.

González Vázquez, Marta, El arzobispo de Santiago: una instancia de poder en la Edad Media (1150-1400), Sada [A Coruña]: Ediciós do Castro, 1996.

Gutiérrez González, José Avelino, Fortificaciones y feudalismo en el origen y formación del reino leonés (siglos IX-XIII), Valladolid: Universidad de Valladolid, D.L. 1995.

- (ed.), Peñaferruz (Gijón). El castillo de Curiel y su territorio, Gijón: Ayuntamiento de Gijón; VTP Editorial, 2003.

Gutiérrez González, José Avelino y Suárez Manjón, Patricia, “Castillos y fortalezas feudales en Asturias: metodología para su estudio", Territorio, Sociedad y Poder, 2 (2007), pp. 5-36.

Gutiérrez González, José Avelino y Suárez Manjón, Patricia, "Castillos y fortificaciones feudales en Asturias", en Excavaciones arqueológicas en Asturias 2003-2006, [Oviedo]: Gobierno del Principado de Asturias; Trabe, 2009, pp. 493-517.

Hernández, Francisco J. (ed.), Las rentas del rey. Sociedad y fisco en el reino castellano del siglo XIII, Madrid: Fundación Ramón Areces, 1993, 2 vols.

Historia Compostellana, ed. Emma Falque Rey, Tvrnholti: Typographi Brepols Editores Pontificii, 1988.

Hydace, Chronique, ed. y trad. Alain Tranoy, París: Les Éditions du Cerf, 1974, 2 vols. 
López Alsina, Fernando, Introducción al fenómeno urbano medieval gallego, a través de tres ejemplos: Mondoñedo, Vivero y Ribadeo, [Santiago de Compostela]: Universidad de Santiago de Compostela, 1976.

López Ferreiro, Antonio, Historia de la Santa A. M. Iglesia de Santiago de Compostela, Santiago de Compostela: Imp. y Enc. del Seminario Conciliar Central, 1904 , t. VII.

López Sabatel, José Antonio, "La villa altomedieval gallega: núcleo de estructuración social y escenario de feudalización", Social and Education History, 2/1 (2013), pp. 78-100.

López Sangil, José Luis y Vidán Torreira, Manuel (eds.), “Tumbo Viejo de Lugo (Transcripción completa)", Estudios Mindonienses, 27 (2011), pp. 11-373.

Maciñeira y Pardo de Lama, Federico, Bares: puerto hispánico de la primitiva navegación occidental, Santiago de Compostela: Consejo Superior de Investigaciones Científicas, Instituto Padre Sarmiento de Estudios Gallegos, 1947.

Madoz [Ibáñez], Pascual, Diccionario Geográfico-Estadístico-Histórico de España y sus posesiones de Ultramar, Madrid: Est. literario-tipográfico de P. Madoz y L. Sagasti, 1846, t. IV.

Marques, André Evangelista, O casal. Uma unidade de organização social do espaço no Entre-Douro-e-Lima (906-1200), Noia [A Coruña]: Editorial Toxosoutos, 2008.

Novo Güisán, José Miguel, “Las ruinas de la playa de Area (Viveiro, Lugo). Historiografía y mitología de un posible yacimiento arqueológico", Estudios Mindonienses, 16 (2000), pp. 467-505.

Pallares Méndez, María del Carmen y Portela Silva, Ermelindo, “Aproximación al estudio de las explotaciones agrarias en Galicia en los siglos IX-XII”, en Universidad de Santiago de Compostela (ed.), Actas de las I Jornadas de Metodología Aplicada de las Ciencias Históricas. II. Historia Medieval, [Vigo]: Universidad de Santiago de Compostela, D.L. 1975, pp. 95-113.

_ "De la villa del siglo IX a la aldea del siglo XIII. Espacio agrario y feudalización en Galicia”, Asturiensia medievalia, 8 (1995-1996), pp. 47-69.

— "El lugar de los campesinos. De repobladores a repoblados", en Ana Rodríguez [López] (ed.), El lugar del campesino. En torno a la obra de Reyna Pastor, [Valencia; Madrid]: Universitat de València; CSIC, 2007.

- "Para una lectura histórica del paisaje. La impronta medieval", en Gerardo Pereira-Menaut y Ermelindo Portela Silva (eds.), El territorio en la historia de Galicia: organización y control, siglos I-XXI, Santiago de Compostela: Universidad de Santiago de Compostela, 2015, pp. 97-151.

Pardo Fernández, Noelia, "La Pasión de Cristo en la pintura gótica lucense. La obra del "Maestro de Mondoñedo". Los murales de la iglesia de Santa María de Vila do Medio de Burela", en José Antonio Rodríguez Mouriño (ed.), XXI Ruta Cicloturística del Románico Internacional, [Pontevedra]: Fundación Cultural Rutas del Románico, [2003], pp. 215-218.

Pardo de Guevara y Valdés, Eduardo, "Vellas e novas liñaxes en Galicia ó final da Idade Media. Unha visión panorámica / Viejos y nuevos linajes en Galicia al final de la Edad Media. Una visión panorámica", en Galicia románica e gótica / Galicia románica y gótica, [Santiago de Compostela]: Xunta de Galicia; Deputación de Ourense; Concello de Ourense; Caixa Ourense, D.L. 1997, pp. 263-283. 
— "Parentesco y nepotismo. Los arzobispos de Santiago y sus vínculos familiares. Siglos XIV-XV", en Ramón Yzquierdo Perrín (ed.), Los coros de catedrales y monasterios: arte y liturgia, [A Coruña]: Fundación Pedro Barrié de la Maza, D.L. 2001, pp. 63-119.

Pena Domínguez, Ricardo, Burela, Lugo: [Asociación de Amas de Casa de Burela], 1985.

Pena Domínguez, Ricardo, Burela. Apuntes históricos y crónica del siglo XX, Lugo: Diputación Provincial de Lugo, D.L. 2004.

Pérez de Tudela y Velasco, María Isabel, “El castillo señorial. En su contexto histórico", en Juan Antonio Barrio Barrio y José Vicente Cabezuelo Pliego (eds.), La fortaleza medieval. Realidad y símbolo, [Murcia]: Sociedad Española de Estudios Medievales; Ayuntamiento de Alicante; Universidad de Alicante; Fundación de Estudios Medievales Jaime II, 1998, pp. 163-176.

Pérez Losada, Fermín, Fernández Fernández, Adolfo y Vieito Covela, Santiago, "Toralla y las villas marítimas de la Gallaecia atlántica. Emplazamiento, arquitectura y función", en Carmen Fernández Ochoa, Virginia García-Entero y Fernando Gil Sendino (eds.), Las villae tardorromanas en el occidente del Imperio: arquitectura y función, Gijón: Trea, 2008, pp. 481-493.

Portela Silva, Ermelindo y Pallares Méndez, María del Carmen, “Os mosteiros, protagonistas da colonización e do proceso de señorialización na Galicia medieval: o exemplo do mosteiro de Sobrado", Estudis d'història agrària, 2 (1979), pp. 51-71.

— "La villa, por dentro. Testimonios galaicos de los siglos X y XI", Studia historica, Historia medieval, 16 (1998), pp. 13-43.

Presedo Garazo, Antonio, "Elite hidalga y poder señorial en Galicia: principales mecanismos de acceso (1480-1650)", Studia historica, Historia moderna, 37 (2015), pp. 123-151.

Ramil González, Emilio, Historia de Cariño da prehistoria á etapa altomedieval: escavacións arqueolóxicas na comarca do Ortegal, Cariño [A Coruña]: Concello de Cariño, 1999.

- Inventario do patrimonio cultural do concello de Cariño: patrimonio arqueolóxico, etnográfico, histórico, Cariño [A Coruña]: Concello de Cariño, 1999.

— "Intervención arqueolóxica no Castro dos Prados, Espasante (Ortigueira, A Coruña)", Brigantium, 12 (2000), pp. 175-178.

- "I Campaña de excavación arqueolóxica na Eirexa Vella-Bares (Mañón)", Brigantium, 12 (2000), pp. 215-218.

Ramil González, Emilio y Picos Brage, Felipe, Escavación arqueolóxica e rehabilitación arquitectónica da capela de San Xiao de Trebo (Cariño-A Coruña), A Coruña: Deputación Provincial da Coruña, D.L. 2002.

Ramil González, Emilio... [et al.], "Villa romana de Bares: escavación arqueolóxica no xacemento Eirexa-Vella de Bares, Concello de Mañón (A Coruña). Campaña 1997", Brigantium, 14 (2003), pp. 185-224.

Ramil Rego, Eduardo... [et al.], "El yacimiento de Punta do Castro (Reinante, Barreiros, Lugo): materiales de superficie y perspectivas", Férvedes, 2 (1995), pp. 87-115.

Río Otero, Marco Antonio, "Burela: de aldea a cidade. Desenvolvemento urbano dunha vila costeira lucense", Boletín do Museo Provincial de Lugo, 10 (20012002), pp. 319-342. 
Ríos Rodríguez, María Luz, "El casal medieval gallego: contribución al estudio de una unidad de poblamiento y explotación (siglos XI a XIII)", El Museo de Pontevedra, XLIII (1989), pp. 109-128.

Rodríguez Colmenero, Antonio, Ferrer Sierra, Santiago y Álvarez Asorey, Rubén D., Miliarios e outras inscricións viarias romanas do Noroeste hispánico (conventos bracarense, lucense e asturicense), Santiago de Compostela: Consello da Cultura Galega, 2004.

Rodríguez Galdo, María Xosé, Señores y campesinos en Galicia. Siglos XIV-XVI, Santiago de Compostela: Pico Sacro, 1976.

Rodríguez González, Ángel, Las fortalezas de la mitra compostelana y los "irmandiños". Pleito Tabera-Fonseca, [Santiago de Compostela]: Fundación Pedro Barrié de la Maza, 1984, 2 vols.

Rodríguez González, Ángel y Rey Caiña, José Ángel (transc. y est.), “Tumbo de Lorenzana", Estudios Mindonienses, 8 (1992), pp. 11-324.

Rodríguez Lestegás, Francisco, "A Galicia cantábrica: xeografía física”, en José Ramón Chantada Acosta... [et al.], Xeografía. A Galicia cantábrica, ártabra e fisterrá, t. XVIII del "Proxecto Galicia", A Coruña: Hércules de Ediciones, D.L. 1996, pp. 20-65.

Rodríguez López, Carlos, Vázquez Varela, José Manuel y Camino Mayor, Jorge, "Concheros castreños y romanos del Cantábrico occidental (Asturias y Galicia)", Gallaecia, 24 (2005), pp. 61-73.

Rodríguez Resino, Álvaro, Do Imperio Romano á Alta Idade Media. Arqueoloxía da tardoantigüidade en Galicia (séculos V-VIII), Noia [A Coruña]: Editorial Toxosoutos, 2005.

Romero Masiá, Ana María, “Asentamentos castrexos costeiros no norde de Galicia”, Gallaecia, 6 (1980), pp. 61-80.

Rubio Martínez, Amparo, "Los primeros vizcondes de Altamira en la villa de Viveiro: adquisición y pérdida de un señorío en el Reino de Galicia", Cuadernos de Estudios Gallegos, LIX/125 (2012), pp. 95-114.

Saavedra Rivadeneyra y Aguiar Pardo de Figueroa, Fernando de, Memorial de la Casa de Saavedra, Granada: Imprenta Real de Francisco de Ochoa, 1674.

Sáez [Sánchez], Emilio, "Los ascendientes de San Rosendo: notas para el estudio de la monarquía astur-leonesa durante los siglos IX y X”, Hispania, 30 (1948), pp. 3-75 y 31 (1948), pp. 179-233.

Sánchez Pardo, José Carlos, "Los ataques vikingos y su influencia en la Galicia de los siglos IX-XI", Anuario Brigantino, 33 (2010), pp. 60-75.

— "Poblamiento rural tardorromano y altomedieval en Galicia (ss. V-X): una revisión arqueológica", Archeologia Medievale, 37 (2010), pp. 285-306.

— "Castros, castillos y otras fortificaciones en el paisaje sociopolítico de Galicia (siglos IV-XI)", en Juan Antonio Quirós Castillo y José María Tejado Sebastián (eds.), Los castillos altomedievales en el noroeste de la Península Ibérica, Bilbao: Universidad del País Vasco, 2012, pp. 29-55.

Sánchez Pardo, José Carlos y Galbán Malagón, Carlos J[osé], “Fortificaciones de altura en el entorno de Santiago de Compostela. Hacia un primer análisis arqueológico comparativo", Nailos. Estudios Interdisciplinares de Arqueología, 2 (2015), pp. 125-161. 
Suárez Piñeiro, Ana María, "La explotación del mar en la Galicia romana: el ejemplo de las instalaciones de salazón", Cuadernos de Estudios Gallegos, L/116 (2003), pp. 9-25.

Torres Sevilla-Quiñones de León, Margarita, Linajes nobiliarios en León y Castilla (siglos IX-XIII), Valladolid: Junta de Castilla y León, 1999.

Valdés Hansen, Felipe, "Origen y consolidación de la actividad ballenera en Galicia: los puertos de la Mariña Lucense en la Baja Edad Media", en Manuel Alfonso Valín Valdés, Carlos Andrés González Paz y Juan Ramón Fernández Pacios (coords.), O Mariscal Pardo de Cela e o seu tempo, [Lugo]: Diputación Provincial de Lugo, 2006, pp. 441-475.

Valdés Hansen, Felipe, Los balleneros en Galicia (siglos XIII al XX), A Coruña: Fundación Pedro Barrié de la Maza, 2010.

Vázquez Varela, José Manuel y Rodríguez López, Carlos, "Nuevos datos acerca de el aprovechamiento de los recursos marinos en los castros de la costa cantábrica gallega: el yacimiento de A Devesa (Ribadeo, Lugo)", Boletín do Museo Provincial de Lugo, 8/1 (1997-1998), pp. 91-123.

- "El aprovechamiento de los recursos marinos en la Prehistoria y la Antigüedad de Galicia”, Boletín do Museo Provincial de Lugo, 9 (1999-2000), pp. 335-365.

Vigo García, Abel, Protohistoria e Romanización na Mariña Lucense: un exemplo práctico, o Castro de Zoñán, Santiago de Compostela: Universidad de Santiago de Compostela, 2007.

Villaamil y Castro, José, “El mariscal Pardo de Cela”, Galicia Histórica, I/2 (1901), pp. 83-98.

Xunta de Galicia, Dirección Xeral do Patrimonio Cultural, Servizo de Arqueoloxía, Inventario de xacementos arqueolóxicos, claves de identificación de los expedientes: GA27902001, GA27902002, GA27902003, GA27902004, GA27902005 y GA27902006.

Zolle [Betegón], Luis, "Transcripción”, en Felipe Pereda [Espeso] y Fernando Marías [Franco] (eds.), El Atlas del Rey Planeta. La «Descripción de España y de las costas y puertos de sus reinos» de Pedro Texeira (1634), $2^{\mathrm{a}}$ edic., Hondarribia [Guipúzcoa]: Nerea, 2002, pp. 305-358. 